\title{
Two independent methods for mapping the grounding line of an outlet glacier - an example from the Astrolabe Glacier, Terre Adélie, Antarctica
}

\author{
E. Le Meur ${ }^{1,2}$, M. Sacchettini ${ }^{1,2}$, S. Garambois ${ }^{3}$, E. Berthier ${ }^{4}$, A. S. Drouet ${ }^{1,2}$, G. Durand ${ }^{1,2}$, D. Young ${ }^{5}$, \\ J. S. Greenbaum ${ }^{5}$, J. W. Holt ${ }^{5}$, D. D. Blankenship ${ }^{5}$, E. Rignot ${ }^{6,7}$, J. Mouginot ${ }^{6}$, Y. Gim ${ }^{7}$, D. Kirchner ${ }^{8}$, B. de \\ Fleurian $^{1,2}$, O. Gagliardini ${ }^{1,2,9}$, and F. Gillet-Chaulet ${ }^{1,2}$ \\ ${ }^{1}$ CNRS, LGGE, UMR5183, 38041 Grenoble, France \\ ${ }^{2}$ Université de Grenoble Alpes, LGGE, UMR5183, 38041 Grenoble, France \\ ${ }^{3}$ ISTerre, UJF-Grenoble, CNRS, Saint Martin d'Héres, France \\ ${ }^{4}$ LEGOS, CNRS, Université de Toulouse, Toulouse, France \\ ${ }^{5}$ Institute for Geophysics, University of Texas, Texas, USA \\ ${ }^{6}$ Earth System Science, University of California, Irvine, California, USA \\ ${ }^{7}$ Jet Propulsion Laboratory, California, Institute of Technology, Pasadena, California, USA \\ ${ }^{8}$ University of Iowa, Department of Physics and Astronomy, Iowa City, Iowa, USA \\ ${ }^{9}$ Institut Universitaire de France, Paris, France \\ Correspondence to: E. Le Meur (lemeur@lgge.obs.ujf-grenoble.fr)
}

Received: 24 June 2013 - Published in The Cryosphere Discuss.: 8 August 2013

Revised: 4 June 2014 - Accepted: 13 June 2014 - Published: 24 July 2014

\begin{abstract}
The grounding line is a key element of coastal outlet glaciers, acting on their dynamics. Accurately knowing its position is fundamental for both modelling the glacier dynamics and establishing a benchmark for later change detection. Here we map the grounding line of the Astrolabe Glacier in East Antarctica $\left(66^{\circ} 41^{\prime} \mathrm{S}, 140^{\circ} 05^{\prime} \mathrm{E}\right)$, using both hydrostatic and tidal methods. The first method is based on new surface and ice thickness data from which the line of buoyant floatation is found. The second method uses kinematic GPS measurements of the tidal response of the ice surface. By detecting the transitions where the ice starts to move vertically in response to the tidal forcing we determine control points for the grounding line position along GPS profiles. Employing a two-dimensional elastic plate model, we compute the rigid short-term behaviour of the ice plate and estimate the correction required to compare the kinematic GPS control points with the previously determined line of floatation. These two approaches show consistency and lead us to propose a grounding line for the Astrolabe Glacier that significantly deviates from the lines obtained so far from satellite imagery.
\end{abstract}

\section{Introduction}

For glaciers and ice streams draining ice sheets to the sea, the transition between the inner grounded ice and its outer floating counterpart defines the grounding line (GL). This line represents a fundamental transition in ice dynamics, separating two drastically different ice flow regimes: sheardominant flow for the grounded part, and longitudinal-stressdominant flow for the floating shelf (see, for instance, Pattyn et al., 2006). Proper demarcation of the GL is required for determining appropriate model discretization and mechanical equations (Durand et al., 2009, Schoof, 2007).

A second issue is that the grounded ice lying above sea level contributes to sea level rise when it passes through the grounding line and goes afloat. As a consequence, proper ice flow budgets for outlet glaciers require knowledge of ice thickness at the location of the GL, and preferably just upstream given the high melting rates encountered in the vicinity and downstream of the grounding line (Depoorter et al., 2013). Using an ice thickness far downstream of the GL can significantly underestimate the ice flux given the importance of mass exchange (mainly melting) between the floating ice 


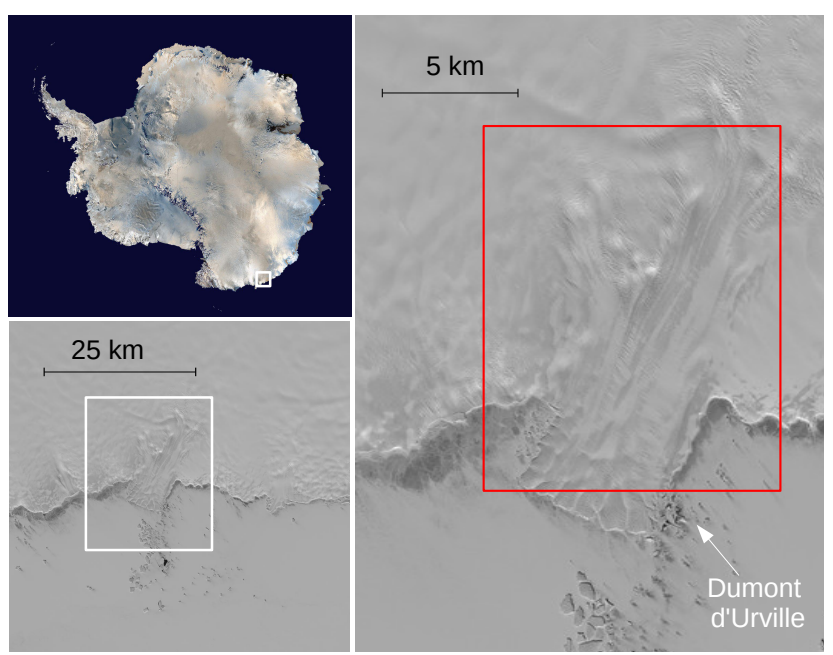

Figure 1. Location of the Astrolabe Glacier in the Terre Adélie sector of East Antarctica from an Advanced Very High Resolution Radiometer (AVHR) global picture (upper left). The regional view (lower left) as well as the focus on the coastal part of the glacier (right) come from a SPOT High Resolution Geometric (HRG1) image taken on the 28 November 2003 (CCNES/Distribution Spot Image). The red square shows the location of Fig. 4.

and the ocean (see for instance Gagliardini et al., 2010; Rignot and Jacobs, 2002; Joughin and Padman, 2003). Given the availability of ice surface velocities over floating ice (Rignot et al., 2011; Joughin et al., 1998) and a low vertical velocity gradient due to a lack of basal drag on the floating ice, accurate computations of the ice flux close to the grounding line are now becoming possible (Shepherd et al., 2012).

In this paper we carefully evaluate two methods for locating the grounding line using Astrolabe Glacier in East Antarctica's Terre Adélie as a test case. Astrolabe Glacier lies immediately next to the French Dumont d'Urville Station (see location in Fig. 1) and thus has been uniquely accessible for a variety of geophysical investigations. Using a diverse range of ground, airborne and spaceborne data, we constrain, at intermediate resolution (of the order of $1 \mathrm{~km}$ ), the grounding line of Astrolabe Glacier using hydrostatic and tidal methods.

\section{Methods for locating the grounding line}

There have been numerous large-scale attempts for delineating the GL around Antarctica using various ground, air or spaceborne techniques. The identification of the GL is complicated by the finite elastic properties of ice, which broaden the surface expression of the GL into a wider grounding zone (GZ). The GZ feature most widely mapped is Ib (see Fig. 2, adapted from that of Brunt et al., 2010), a characteristic slope break thought to represent change from basal drag to no basal drag. However, additional features of the GZ re-

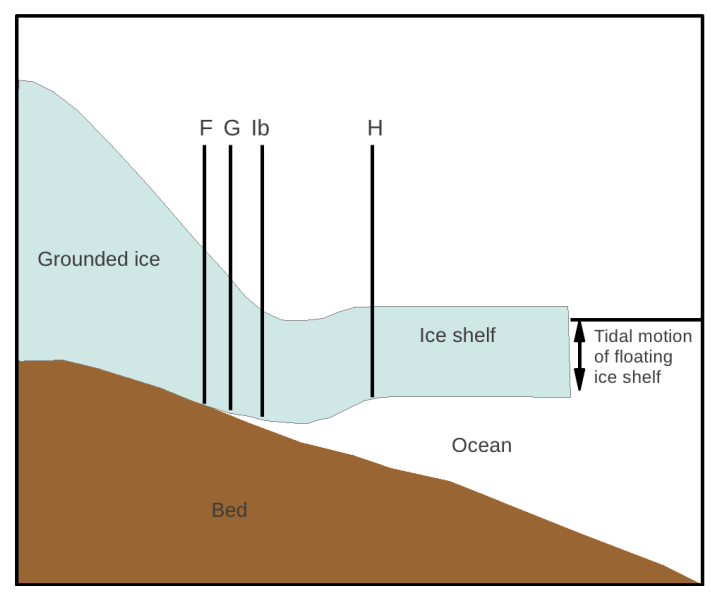

Figure 2. Important points along the transition between grounded and floating ice: $F$ represents the landward limit of tidally induced vertical displacements; $\mathrm{G}$ is the grounding line where the ice bottom actually separates from the ground; Ib is the so-called "break in slope"; and $\mathrm{H}$ is the limit where the rigid effects of the elastic bending of the ice slab do not propagate any further, allowing the ice to freely float on the ocean (adapted from Brunt et al., 2010).

lating to ocean dynamics and buoyancy provide a more direct proxy of the ice-rock separation.

Buoyancy considers the ice slab in its long-term interaction with an "averaged, non-tidal" ocean under the form of a predominantly viscous deformation when the ice comes to floatation (see Fig. 3). As a result, the transmission of rigid stresses is reduced, allowing the hydrostatic approach in a first determination of the GL.

On the other hand, tidally induced changes in the ice upper surface can be recorded to provide a dynamical proxy for the GL from the boundary between mobile and immobile upper surface areas. Over the shorter-term forcing of the tides (hourly to daily), rigid stresses become more pronounced (the ice behaving more elastically; Vaughan, 1995), which leads to a regional tidal flexure of the plate over the full $\mathrm{F}-\mathrm{H}$ distance (Fig. 3). $\mathrm{F}$ is the landward limit of the ice upper deformation under tidal forcing whereas $\mathrm{H}$ is the seaward limit of the rigid effects where free floatation is recovered (Fricker and Padman, 2006). The contact point (icerock separation) moves from point $\mathrm{G}_{\mathrm{H}}$ at high tide (landward of $G$ ) to point $G_{L}$ (seaward of $G$ ) at low tide. An alternative for the GL positioning consists of considering the series of F points which undergo the first vertical displacements at the ice upper surface (Fig. 3). Points actually mapped with GPS (X points) will then lie seaward, but very close to the F points as the detection threshold of the kinematic method used is small (for instance, 10 to $20 \mathrm{~cm}$ with Ice, Cloud and land Elevation Satellite (ICESat) laser altimetry (Fricker and Padman, 2006) or less than $1 \mathrm{~cm}$ with differential satellite synthetic aperture radar interferometry (DInSAR; Rignot et al., 2011)). The situation is complicated by the rigid tilting of 
the slab which exerts a bending moment that lifts the outer fringe while the ice-bedrock contact point migration is limited to the GL high-tide position $\mathrm{G}_{\mathrm{H}}$ (Fig. 3). The resulting $\mathrm{F}-\mathrm{G}$ offset (more specifically the $\mathrm{X}-\mathrm{G}$ offset) is therefore responsible for the difference between a hydrostatic and a kinematic grounding line determination. Modelling the tidally induced flexure of the ice slab is a way of assessing these distances and hence the consistency between the hydrostatic and kinematic approaches as carried out in the present study. The three approaches for mapping the grounding line (the hydrostatic method, the tidal method and the surface slope method) allow identification of GZ features. Combining these methods helps define the GL location.

\subsection{Hydrostatic methods}

Hydrostatic methods use Archimedes' Principle to estimate from surface elevation data the ice thickness required for a column of ice to float; this estimate is compared to measured ice thickness data to calculate "floatation" (Robin et al., 1983; Corr et al., 2001). Where the two numbers are the same, the ice is floating. Errors in this method come from neglecting rigid internal stresses within the ice slab and errors in surface elevation, the value of the ice-water density contrast, and the surface elevation as well as in ice thickness estimates.

\subsection{Tidal methods}

Tidal methods consist of tracking time-dependent surface elevation changes generated by the tides (e.g. Fricker and Padman, 2006). Differential satellite synthetic aperture radar interferometry (DInSAR) has been widely employed for mapping the 2-D time-dependent vertical displacement field in response to tidal forcing (Rignot, 1998; Goldstein et al., 1993). Usually the line of F points is considered a good representation of the GL. The variation in results from different studies arises from different detection thresholds in the measurement methods, leading to various downflow shifts in the points actually measured. Because of a very low noise level for their DInSAR method (less than $1 \mathrm{~cm}$ vertical displacement), Rignot et al. (2011) obtain a detectable tidal signal shortly below the $\mathrm{F}$ line (before the $\mathrm{G}$ point) which they consider as the true GL. In some cases, such as Petermann Glacier, the F-G distance is sufficiently narrow $(500 \mathrm{~m}$ to $1 \mathrm{~km}$; Rignot et al., 2011) that the difference between mapping $\mathrm{F}$ or $\mathrm{G}$ is not very significant.

Similar to DInSAR, temporal changes of ice surface elevation have also been assessed from ICESat repeat-track altimetry at different tidal phases (see, for instance, Fricker and Padman (2006), Brunt et al. (2010) and references therein), the main limitation being a discrete number of tracks that only cross the grounding line at points spaced approximately $10 \mathrm{~km}$ along much of the Antarctic coast. This method also theoretically maps the inner limit of surface deformation ( $F$

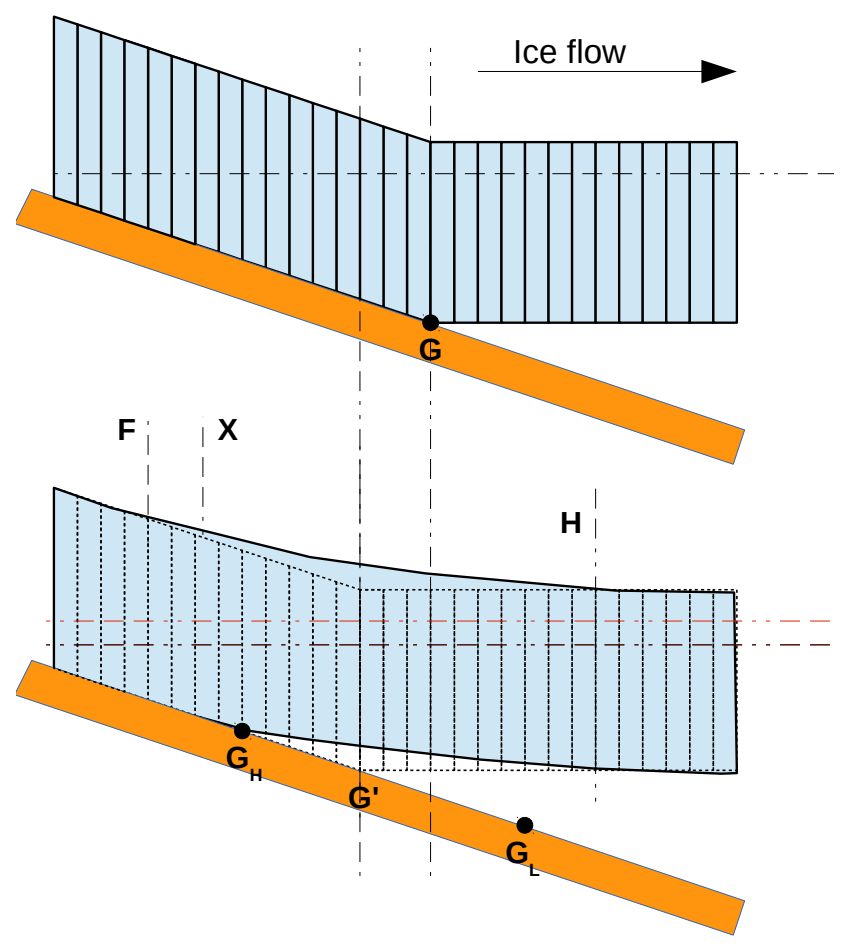

Figure 3. Ice-ocean interactions near the grounding line. The top of the figure represents the grounded-floating transition for an outlet glacier where hydrostatic equilibrium with a constant "non-tidal" ocean is assumed throughout. The lack of rigid stresses is here illustrated by blocks floating independently from one another. The floatation criterion allows a first estimation of the contact point $\mathrm{G}$. The situation as depicted at the top is supposed to represent an average sea level between low and high tides. The bottom of the figure now considers the effects of the tidal rise (red line) superposed on top of the previous reference state. Should the response remain purely hydrostatic, tidal deformation would only span the $\mathrm{G}-\mathrm{G}^{\prime}$ distance, therefore representing an underestimated migration of the grounding line. In fact, the tidally short-term forcing implies a rigid behaviour, making the deformation spread over the entire grounding zone $(\mathrm{FH})$, now implying a more realistic migration for the grounding line. As a result, ice surface movements are to be expected from $\mathrm{F}$ and will become detectable after a certain distance seaward (at point $\mathrm{X}$ ) depending on the detection threshold of the kinematic method used.

points), but a higher noise level likely induces larger offsets towards $\mathrm{G}$ for the points actually detected. $\mathrm{H}$ points (full floatation recovery) are also mapped, giving the grounding zone width $(\mathrm{F}-\mathrm{H})$. Contrary to Petermann Glacier, much larger grounding zones are found on the Ross Ice Shelf, with an average width of $3.2 \mathrm{~km}$ (2.6 km standard deviation) and sometimes exceeding $10 \mathrm{~km}$ for the study area of Brunt et al. (2010). Given the fact that the considered true grounding line $\mathrm{G}$ can be situated anywhere within this grounding zone, it is sometimes difficult to assess the accuracy of the proposed positioning. However, wide grounding zones often characterize large outlet glaciers for which uncertainties in the grounding 
line position of the order of $1 \mathrm{~km}$ in the proposed kinematic methods (Fricker and Padman, 2006; Brunt et al., 2010) still provide a useful refinement as compared to previous results from different satellite methods based on the identification of specific topographic features.

\subsection{Surface slope methods}

Surface slope methods rely on the identification of smallscale surface topographic features from visible satellite imagery or a digital elevation model (DEM). These features comprise flow stripe disruption, surface manifestation of basal crevasses or a break in the surface slope (Ib) all of which are inferred to appear where the ice starts to float (Brunt et al., 2010). Scambos et al. (2007) used a constrained range of sun illumination (optimized for the expression of surface slopes) in the Moderate Resolution Imaging Spectroradiometer (MODIS) mosaic image of Antarctica allowing for the determination of the break in slope (Ib) to infer a grounding line location. Horgan and Anandakrishnan (2006) used a surface slope analysis from a high-resolution DEM derived from ICESat data. Bindschadler et al. (2011) used a surface slope method combining optical imagery (Landsat) with sparse ICESat altimetry for mapping the seaward limit of grounded ice features that best corresponds to Ib and constitutes their Antarctic Surface Accumulation and Ice Discharge (ASAID) GL. Bindschadler et al. (2011) provided a low-resolution version of $\mathrm{H}$, the limit at which ice is freely floating, using a tidal analysis of the sparse ICESat data.

\subsection{Differences in results}

Tidal and hydrostatic methods appear to provide more reliable determination of the GL but are temporally and spatially limited by data availability. On the other hand, surface slope methods can use satellite imagery extending back more than 30 years and are not limited by decorrelation due to changing environmental effects. This paper represents the first mapping of the Astrolabe Glacier grounding line using tidal methods and fills a gap in the Rignot et al. (2011) tidal grounding line data set.

Rignot et al. (2011) find that their grounding line mapping obtained from DInSAR often deviates from the lines obtained using break-in-slope techniques by as much as several tens of kilometres, especially on fast moving outlet glaciers. Conversely, on more stagnant and slow-moving ice, tidal and surface slope methods are typically in agreement. The approach employed by Rignot et al. (2011) is also a tidal method and therefore consistent with those based on ICESat data, with the main difference being a continuous mapping along the grounding line and lower detection noise (vertical motion measured with less than a centimetre precision).

In the present paper, after describing the approach, we present the first map of the Astrolabe Glacier GL derived from new bedrock and ice surface elevation data by apply- ing the hydrostatic criterion. A ground-based tidal approach, using kinematic GPS measurements of the tidally induced displacement pattern of the ice slab is then used for inferring vertically moving and immobile areas of the glacier. With the help of a 2-D elastic rigid flexure model, the consistency between the two approaches is verified. A reliable grounding line positioning at intermediate resolution is then proposed for comparisons with published GL locations using the surface slope criterion.

\section{Hydrostatic grounding line position}

Assuming an average density $\rho_{\mathrm{i}}$ for the ice column, a theoretical floatation depth $P$ can be easily computed from the ice upper elevation above sea level $h$ according to

$P=\frac{\rho_{\mathrm{i}} h}{\rho_{\mathrm{W}}-\rho_{\mathrm{i}}}$,

with $\rho_{\mathrm{w}}$ a sea water density of $1028 \mathrm{~kg} \mathrm{~m}^{-3}$ (Craven et al., 2005). Comparison of this depth with the depth of the ice bottom obtained from radar soundings indicates whether the ice is freely floating or is grounded.

\subsection{Ice upper surface}

To compute hydrostatic profiles we use ice surface elevation data obtained from a $40 \mathrm{~m}$ DEM available for the entire Astrolabe Glacier. Surface heights were calculated from a pair of stereoscopic images acquired on 14 December 2007 by the SPOT 5-HRS (High Resolution Stereoscopic) sensor in the framework of the SPIRIT (SPOT 5 stereoscopic survey of Polar Ice: Reference Images and Topographies) International Polar Year (IPY) project (Korona et al., 2009).

We validate the vertical accuracy of the SPIRIT DEM using the ICESat-1 Release 33 product acquired during laser period 3I (Zwally et al., 2005), only 54 days before the SPOT 5 stereo pair. To complete the comparison we first convert the ICESat-1 elevation data to altitude above the Earth Gravitational Model 1996 (EGM96) geoid to match the datum of the SPIRIT DEM. For each ICESat footprint the corresponding DEM elevation was extracted using bilinear interpolation.

When correlation artifacts are discarded using the correlation mask provided with the elevation data set, the mean vertical bias is $-0.3 \mathrm{~m}$ (standard deviation $2.9 \mathrm{~m}, N=2319$ ). For the part of the Astrolabe Glacier studied here (close to and downstream of the grounding line), there are very few interpolated pixels because the glacier surface is highly crevassed (feature rich) and SPOT 5 images have a good radiometric dynamic range. Thus, we consider $\pm 3 \mathrm{~m}$ to be the uncertainty of the ice surface elevation.

\subsection{Ground-penetrating radar survey}

The Astrolabe Glacier has been the target of several recent radar campaigns with an emphasis on the coastal part of the 


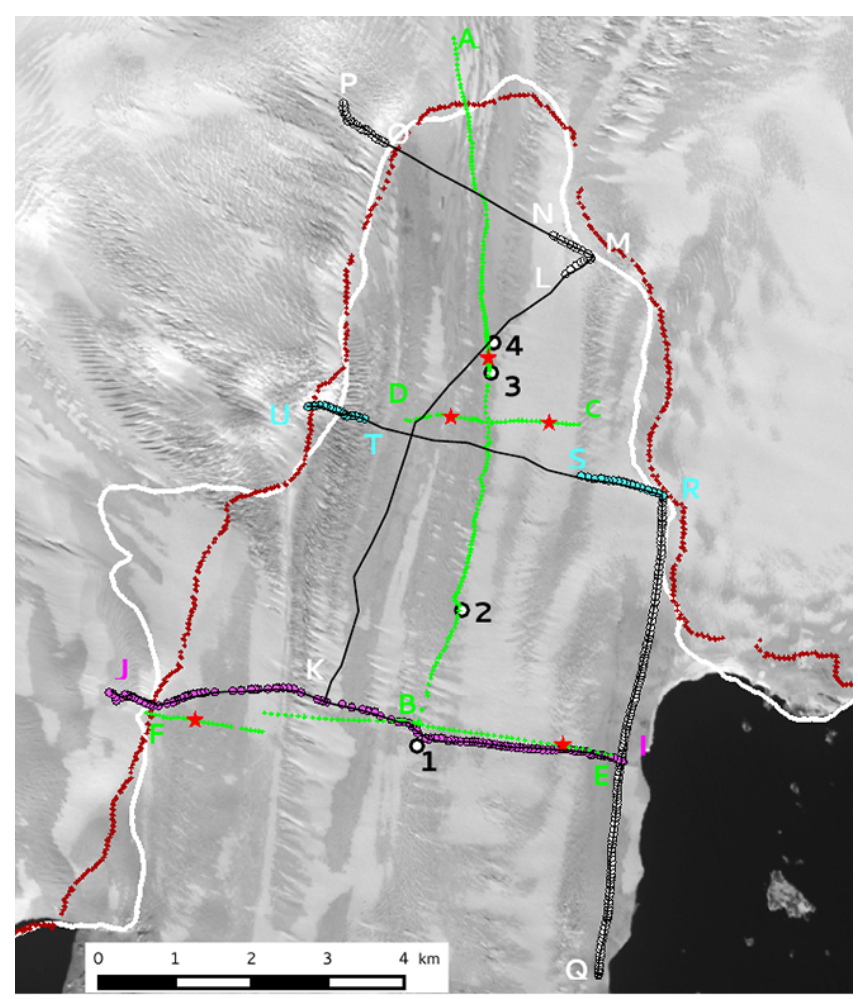

Figure 4. Summary map of field activities carried out on the surface of the Astrolabe Glacier superimposed on an Advanced Spaceborne Thermal Emission and Refection Radiometer (ASTER) image. The thin black line outlines the ground radar profiles acquired and the overlapping coloured dots indicate where the ice bottom echo was detectable and a depth could be inferred. Green dots represent each of the points measured twice by kinematic GPS in order to detect the difference in ice surface elevation between low and high tides and the red stars indicate the resulting "GPS control points" (see Sect. 4.1). Points 1 to 4 indicate where surface elevation was continuously monitored by GPS for several days (Sect. 4.2.2). Lastly, the white and brown lines are the grounding lines proposed by Bindschadler et al. (2011) and Scambos et al. (2007) respectively.

glacier (Fig. 4). Ground-penetrating radar (GPR) measurements were acquired along several profiles with a MALA ${ }^{\circledR}$ ProEx GPR system connected to a $50 \mathrm{MHz}$ Rough Terrain Antenna, which was towed by the operator on the ground. Measurements were acquired with a constant offset of $4 \mathrm{~m}$ between the transmitter and the receiver antennae. Acquisition was triggered every $5 \mathrm{~m}$ for all profiles and was automatically controlled using a calibrated encoder wheel. After acquisition the data were repositioned with GPS measurements which allowed straightforward derivation of topography information. Data were acquired with a sampling frequency of $648 \mathrm{MHz}$ over a $12.8 \mu$ s time window and stacked 32 times.

The GPR data were processed using the Seismic Unix software (www.cwp.mines.edu/cwpcodes). The processing sequence includes time-zero corrections and a dewow zerophase low-cut filter to remove direct continuous currents. In
(A)

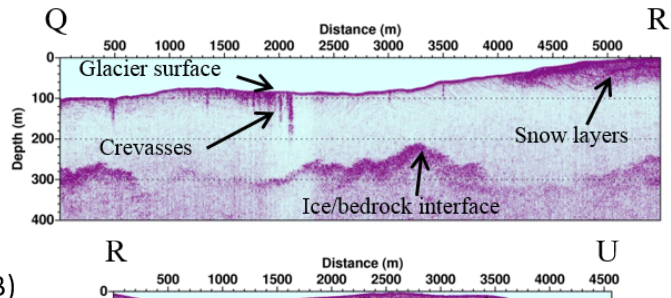

$\mathrm{R}$

(B)

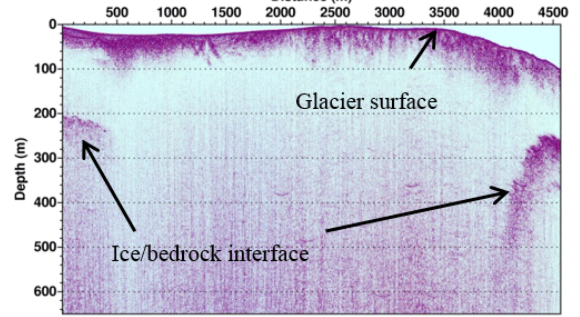

(C)

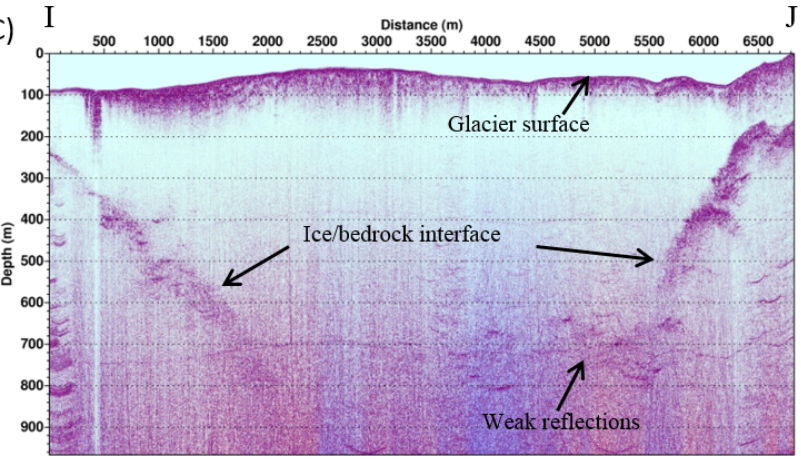

Figure 5. Ice-bedrock interface measured by GPR along profiles [QR] (A), [RU] (B) and [IJ] (C) of Fig. 4. Snow layer horizons become visible on profile [QR] after a distance of $4000 \mathrm{~m}$ when entering the accumulation zone. Combined effects of depth and floating ice seriously alter the reflectors in the middle of profile $[\mathrm{IJ}]$ and lead to a total loss in the middle of profile [RU].

order to improve the signal-to-noise ratio of late arrivals, a zero-phase band-pass filter was also applied to the raw data in the $[30-70 \mathrm{MHz}]$ frequency range. The data were then migrated using a Stolt $\mathrm{f}-\mathrm{k}$ migration algorithm with a constant velocity of $168 \mathrm{~m} \mathrm{us}^{-1}$ in order to correctly locate dipping events and to focus scattering hyperbolae. Finally, for display purposes, topographic corrections and time-to-depth conversions were computed using the same constant velocity.

This classical velocity in cold ice was measured outside of the glacier with common midpoint (CMP) analyses. No firn correction is accounted for, given the fact that the ground radar measurements were almost entirely performed on the lower part of the glacier where accumulated snow is generally turned into ice by the summer melting events that occur there (except over the uppermost part of profile [QR]; see Fig. 5). As topography variations are relatively smooth compared to penetration depth, topography corrections have been computed after migration. A gain was also applied to the data to compensate for spreading signal attenuation.

Surface crevasses (apparent from surface morphology, Fig. 4, and radargrams, middle of Fig. 5a) can corrupt the 
transmitted signal. As a result, ice thickness could only be assessed over limited portions of the radar lines (black lines in Fig. 4; coloured dots show ice thickness observations). For the middle of profile [IJ], the inferred ice thicknesses should be considered with caution in the central part given the extreme weakness of the reflectors. Figure 5 shows processed radargrams corresponding to profiles $[\mathrm{QR}],[\mathrm{RU}]$ and [IJ] (see Fig. 4 for their respective locations).

On profile [QR] (Fig. 5, top), the basal interface is clearly visible as a strong unique reflector along the full profile due to thin ice ranging from 100 to $200 \mathrm{~m}$ on the grounded righthand side of the glacier. On profile [IJ] (Fig. 5, bottom) and profile [RU] (Fig. 5, middle), the basal interface is lost along the centreline of the glacier. This data gap could be due to the penetration limit of the GPR or to a decline in bed reflectivity. Indeed, weak focused hyperbolae are visible on the right side of profile $[\mathrm{IJ}]$ and may result from the rough contact arising when the ice goes afloat (Vaughan et al., 2012). This roughness in the basal interface could be due to saltwater intrusions into bottom crevasses and cracks that create large scattering hyperbolae that are not visible at the ice-bedrock interface (Van der Veen, 1998). Accretion and/or intrusion of marine ice can also be an explanation. For profile [RU], the loss of signal in the central part is abrupt and occurs at different depths, $200 \mathrm{~m}$ on the left and $500 \mathrm{~m}$ on the right, despite post-processing attempts to improve the signal-to-noise ratio.

\subsection{Hydrostatic profiles}

From the upper ice elevation along radar profiles where the ice bottom reflector can be unambiguously identified (coloured dots in Fig. 4), Eq. (1) is used to compute the corresponding theoretical profiles of floatation depths. A density of $1028 \mathrm{~kg} \mathrm{~m}^{-3}$ is commonly accepted for sea water (Craven et al., 2005). Ice density is less well constrained. Various studies dealing with Antarctic ice shelves (Fricker et al., 2001; Wen et al., 2007, 2010) suggest a column-integrated ice density ranging from 880 to $900 \mathrm{~kg} \mathrm{~m}^{-3}$ whereas Bamber and Bentley (1994) find a good fit in the comparison of satellite altimetry and ice thickness measurements with a higher value of $917 \mathrm{~kg} \mathrm{~m}^{-3}$. In the present case, two factors contribute to a short-scale spatial variability of the ice column average density. By creating voids up to $40 \mathrm{~m}$ deep, crevassing, which in some places can be very intense (shear zones for instance), significantly reduces the overall density. On the other hand, the lack of firn in the central lower part of the glacier due to the entire melting of the snow by the end of the summer (ablation zone) is responsible for density values locally close to that of pure ice $\left(917 \mathrm{~kg} \mathrm{~m}^{-3}\right)$. It was therefore decided to adopt a central value of $890 \pm 10 \mathrm{~kg} \mathrm{~m}^{-3}$ for our theoretical floatation computations.

Resulting profiles are depicted in Fig. 6. By denoting the bottom of the ice slab, the radar reflector is normally either above floatation (grounded ice), or lying within the floatation error bars (in floatation or nearly so). As indicated by
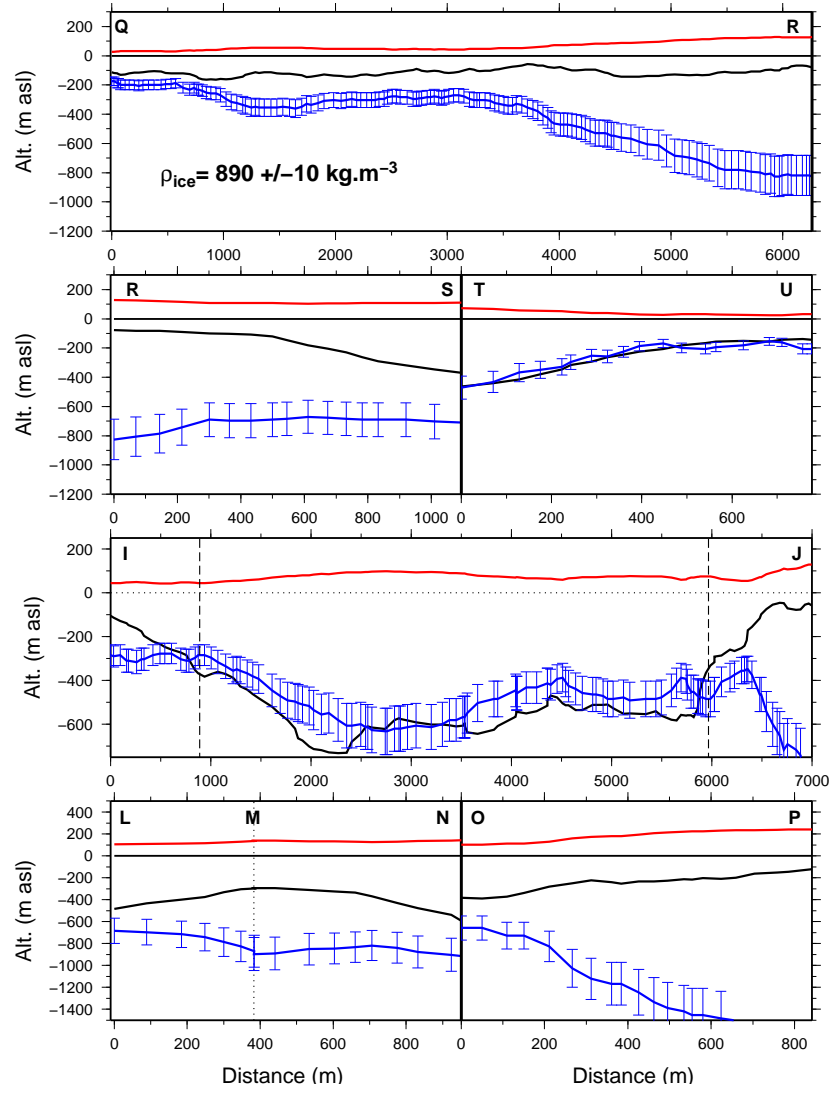

Figure 6. Theoretical hydrostatic floatation depth (blue curve with error bars) computed with an ice density of $890 \pm 10 \mathrm{~kg} \mathrm{~m}^{-3}$ compared to the ice bottom depth (black curve) inferred from groundpenetrating radar operated from the ground. The red curve represents the altitude of the ice surface obtained from the SPIRIT DEM with respect to the EGM96 geoid. The profiles correspond to the coloured dots in Fig. 4. The vertical dashed lines on profile [IJ] show the location of to the two control points for the grounding line position obtained from the GPS kinematic method (see Sect. 4.1).

the error bars, floatation depth uncertainties are sensitive to the ice density range. If the hydrostatic assumption is valid, the floatation curve cannot lie above the bedrock, and these profiles allow for the assessment of a lower bound on the density value. Along profile [TU], for instance, where floatation seems to be met, except perhaps on the rightmost side of the profile, one can see that density values can hardly go below $880 \mathrm{~kg} \mathrm{~m}^{-3}$, lower values would significantly raise the floatation above the bedrock. A closer look shows that the lower-lying left side of the profile seems to favour higher densities (around $900 \mathrm{~kg} \mathrm{~m}^{-3}$ ) whereas the upper one gives a better match with the top of the error bars $\left(880 \mathrm{~kg} \mathrm{~m}^{-3}\right)$ before grounding probably occurs at the very end. This is compatible with a gradient in the firn layer thickness from the lower central part up to the upper sides of the glacier. Similarly, profile $[\mathrm{IJ}]$ tends to indicate higher density values in its central floating part with a better match with the bottom 
of the error bars $\left(900 \mathrm{~kg} \mathrm{~m}^{-3}\right)$. This again can be linked to the fact that the entire profile appears to be deprived of firn. Caution should be taken with the central part of profile [IJ], where the bottom depths result from a partly subjective interpretation of very faint reflectors. There is also a potential uncertainty regarding the depths due to the assumed radar wave propagation speed but the observed lack of firn along most of the profiles justifies using the commonly accepted velocity value of $168 \mathrm{~m} \mathrm{ss}^{-1}$ for ice. This is confirmed by comparing radar depths to two boreholes drilled in close proximity to the radar data (with one along profile $[\mathrm{QR}]$ ). The boreholes reached depths of 153 and $296 \mathrm{~m}$ compared with ground-radar-inferred depths of 150 and $300 \mathrm{~m}$ respectively. Therefore, only slight systematic deviations are to be expected from a possible error on the wave velocity. Plotting error bars on ground radar data is meaningless here as they mainly result from reflector misinterpretation over poorly resolved areas.

In some cases, radar reflectors significantly above the theoretical floatation depth are a clear indicator of grounded ice, such as along profiles [QR], [LN], [OP] and [RS]. Conversely, a good match between profiles (for example profile [TU]) most likely indicates ice which is at or near floatation (except at its very eastern end). Lastly, along profile [IJ] we find grounded ice in its outer parts, which then goes afloat (or partly grounded) in its central part. Based on these results, areas of respective grounded and potentially floating ice for the GZ of Astrolabe Glacier can already be proposed and later refined with the help of extra airborne radar profiles.

\subsection{Supplementary airborne radar data}

As part of a collaborative project with the Jet Propulsion Laboratory (Warm Ice Sounding Explorer, WISE) and The University of Texas Institute for Geophysics (Investigating Cryospheric Evolution through Collaborative Aerogeophysical Profiling, ICECAP; Young et al., 2011), several airborne geophysical campaigns have been undertaken during the 2008/2009, 2009/2010 and 2011/2012 seasons in order to characterize some of the large outlet glaciers of the Wilkes Land-Terre Adélie sector of East Antarctica. Some of the flights were dedicated to the Astrolabe Glacier over which bedrock topography was measured with a combination of medium- $(2.5 \mathrm{MHz})(\mathrm{MF})$ and very high- $(60 \mathrm{MHz})$ frequency (VHF) high-power sounding radars mounted on either a DHC-8 Twin Otter or a DC-3T Basler aircraft. Figure 7 shows one of the MF radar profiles obtained over the glacier along the Y1-Y2 profile as represented in Fig. 8. A treatment similar to that applied to ground radar data was performed and allowed for similar theoretical hydrostatic floatation profiles as those depicted in Fig. 6.

A compilation of floatation results for both ground and airborne data is shown in Fig. 8. The colours give the required density value for the ice slab to reach hydrostatic equilibrium above the ocean given the ice freeboard and the total ice

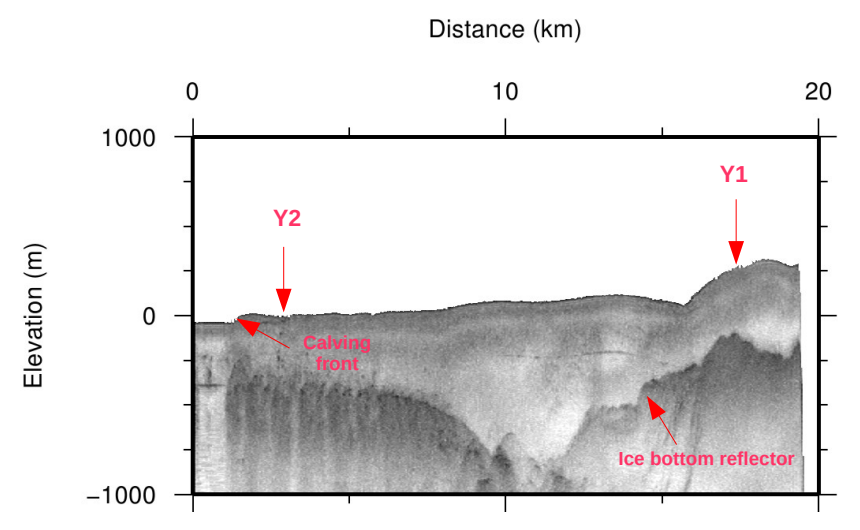

Figure 7. Airborne radar profile corresponding to the $\mathrm{Y} 1-\mathrm{Y} 2$ profile of Fig. 8.

thickness. From the chosen ice density of about $880 \mathrm{~kg} \mathrm{~m}^{-3}$ (accounting for the possible presence of a firn layer as well as crevasses), a first guessed hydrostatic grounding line can be proposed as represented in the figure by the yellow dots. Assuming a density of $900 \mathrm{~kg} \mathrm{~m}^{-3}$ in the present case would significantly reduce the floating shelf and require significant "regrounding" within the basin. Although this possibility cannot be excluded (notably given the rough topography measured below the grounded parts of the glacier), the required amount of grounding appears incompatible with the surface displacements measured in our kinematic approach described below. Local pinning points or even small grounded areas close to floatation are also possible seaward of the proposed GL according to the computed density values (see question marks in the figure).

Attempting to adjust the column average density any further for the sake of refining a hydrostatically derived grounding line does not make sense at this stage because (i) this density varies laterally along the profiles, (ii) errors on the radar depths have to be considered and (iii) the hydrostatic approach remains approximate. Airborne radar sounders, over rough, steep terrain, have some uncertainty in bed echo location due to the large beam spot size due to the aircraft's height above the ice-air interface. The airborne radar beam spot at the basal interface ranges from $1 \mathrm{~km}$ across for the VHF to several kilometres for the MF system and any rough topography in that spot can appear to map directly below the aircraft. As a consequence, the airborne systems have an apparent vertical uncertainty of rms $50 \mathrm{~m}$ in rough, steep areas such as fjord walls. Consequently, we found large differences in crossover ice thickness between the ground and airborne profiles in a few places. For instance the crossing outlined by the green arrow (Fig. 8), near the fjord wall, shows significantly different inferred density values resulting from radar ice thicknesses of 390 and $680 \mathrm{~m}$ for the airborne and ground radar respectively. As a consequence, when outlining our proposed grounding line using the central ice density 


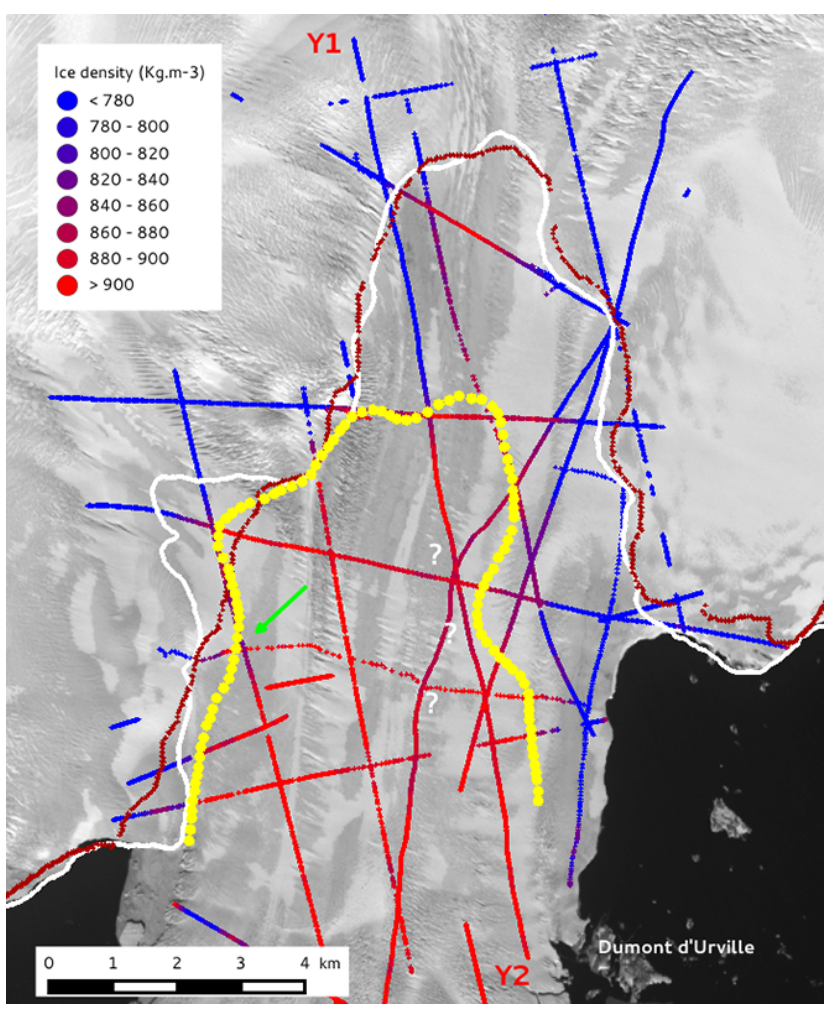

Figure 8. Hydrostatically determined transitions between grounded (blue) and floating (red) ice along all radar profiles performed over the coastal part of the Astrolabe Glacier as a function of the chosen value for ice density. Assuming the central value of $880 \mathrm{~kg} \mathrm{~m}^{-3}$ for the ice density the resulting grounding line is indicated by the yellow line. The green arrow points towards the radar profile intersection where a large discrepancy in ice thickness is observed. Y1 and Y2 denote both ends of the radar profile of Fig. 7. Question marks indicate places of possible partial grounding (pinning points) whereas a significant increase in density some $2 \mathrm{~km}$ inland of the proposed GL denotes the possible presence of an isolated trough. Lastly, the white and brown lines are the grounding lines proposed by Bindschadler et al. (2011) and that of the 2009 updated data set of Scambos et al. (2007) respectively.

value of $880 \mathrm{~kg} \mathrm{~m}^{-3}$, preference was given to ground radar data when they conflicted with the airborne data.

Inspection of Fig. 8 shows various shifts of the floatation point when the chosen density varies. One transition colour represents a $20 \mathrm{~kg} \mathrm{~m}^{-3}$ density change which can more or less be considered as the uncertainty on the ice column average density value. These shifts are generally limited to the sides of the fjord due to rather steep slopes there (the width of a colour being of the order of $250 \mathrm{~m}$ in most cases) but can significantly increase up to $500 \mathrm{~m}$ to $1 \mathrm{~km}$ along flow as the result of less pronounced slopes. An rms of $50 \mathrm{~m}$ on the airborne radar depths leads to an extra uncertainty which also depends on the slope of the bedrock. Figure 6 (profile [IJ]) shows that close to the grounding line, a $\pm 10 \mathrm{~kg} \mathrm{~m}^{-3}$ change usually leads to a $\pm 50 / 100 \mathrm{~m}$ vertical shift of the floatation depth. As a consequence, the uncertainty resulting from errors on radar depths can be assumed to be of the same order as that from errors on density. These error terms being independent, we therefore end up with an overall uncertainty reducing to the larger error source of about $1 \mathrm{~km}$ for the proposed grounding line location.

The proposed grounding line should therefore be considered as a first approximative guess that will later be constrained by the forthcoming proposed kinematic method. Despite the associated uncertainties so far, significant deviations from previous mappings from surface feature identification (Bindschadler et al., 2011; Scambos et al., 2007) are already noticeable, especially on the west flank of the glacier.

\section{Kinematic GPS grounding line position}

As an independent test of GL position, we used a groundbased tidal method of detecting the presence or absence of tidally induced vertical movements of the ice upper surface using kinematic GPS positioning. Profiles of individual measurement points were set up in both along-flow and crossflow direction (see green dots in Figs. 4 and 9).

\subsection{Field differential GPS survey}

This method is very similar to ICESat repeat-track analysis (Brunt et al., 2010) as it consists of measuring the ice surface height along profiles crossing the grounding zone at low and high tides and observing where the two profiles diverge as a result of tidal movement. Tidal amplitude in the sector is $\sim 1 \mathrm{~m}$ (see Fig. 10). As ice shelf vertical displacements are damped by the rigid behaviour of the ice slab confined within a narrow embayment, the method requires a high accuracy in the measurements of the resulting limited vertical displacements of the ice surface. We here used dual carrier-phase differential GPS measurements as in Vaughan (1995). A reference GPS receiver was set up on the nearest rock outcrop, while a rover unit was used to acquire positions according to the "stop and go" method along the profiles (Fig. 9). The corresponding baseline was short enough (less than $15 \mathrm{~km}$ ) so as to ensure real-time radio transmission of appropriate corrective terms (mostly ionospheric and atmospheric delays) from the reference to the rover and to allow for kinematic ambiguity resolution. "Stop" recording phases did not exceed $30 \mathrm{~s}$. Each of the measured points was precisely marked on the ground (using paint) in order for the second measurement to be performed at exactly the same place some 12 hours later. Accurate reoccupation was vital as the small-scale roughness of the glacier surface is such that moving half a metre is enough to change the surface height by as much as several tens of centimetres. 


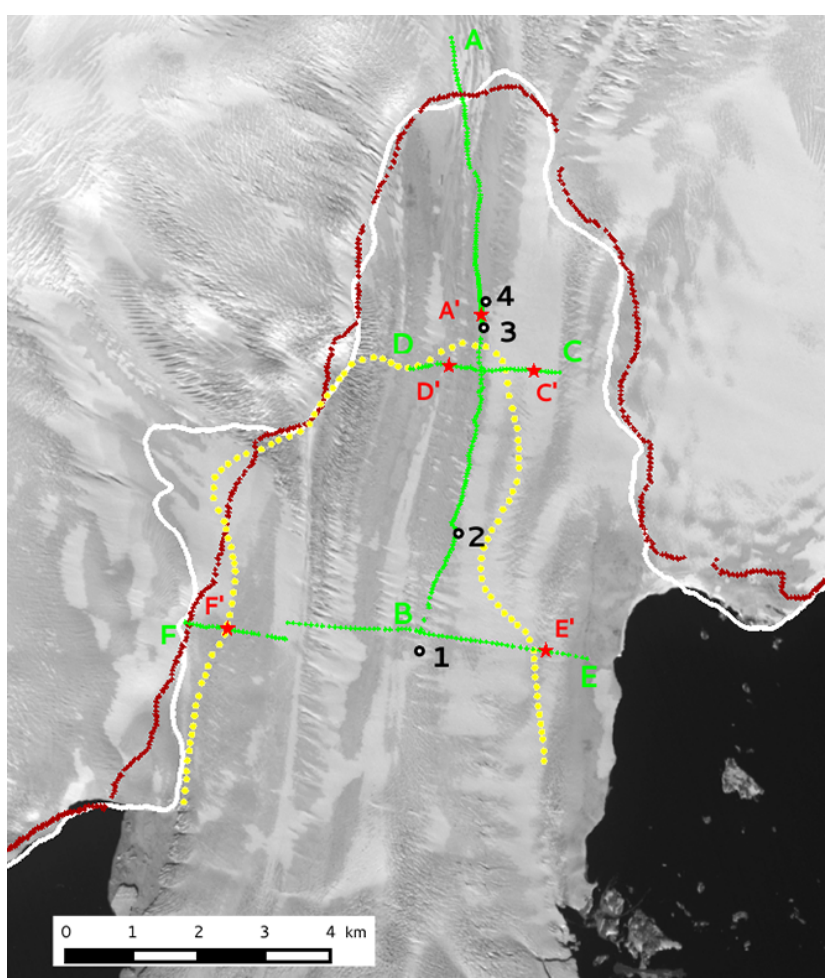

Figure 9. Profiles made of measurement points (green dots) where the ice upper surface was measured by GPS at both low and high tides. Also featured is the grounding line preceding estimation. Red stars (labelled $\mathrm{A}^{\prime}, \mathrm{C}^{\prime}, \mathrm{D}, \mathrm{E}^{\prime}$ and $\mathrm{F}^{\prime}$ ) represent the transition points where this difference becomes significant (see text in Sect. 4.2.1) and points 1 to 4 are the points where GPS has been dropped and has been recording continuously during several tidal cycles (Sect. 4.2.2).

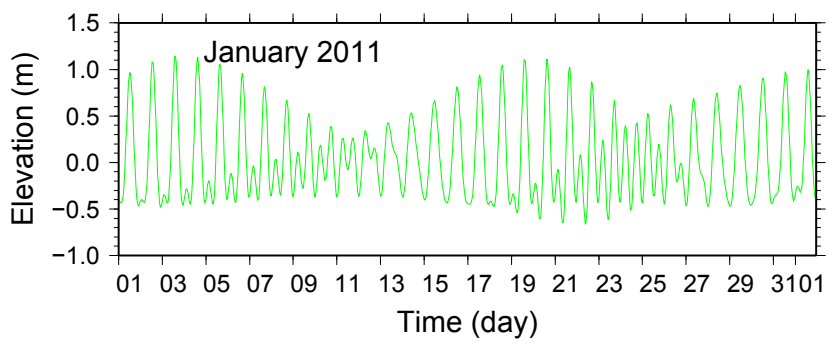

Figure 10. Modelled tides for January 2011 where semi-diurnal, diurnal and fortnightly tidal periods are observable.

\subsection{Time-dependent ocean tides}

The timing of the GPS surveys required identifying the high and low tides. Unfortunately, the tide gauge at the nearby Dumont d'Urville station was not operational and we therefore had to rely on a prediction model (courtesy of Benoît Legrésy; see also Legrésy et al., 2004). Figure 10 shows the model predictions for the tides of January 2011.

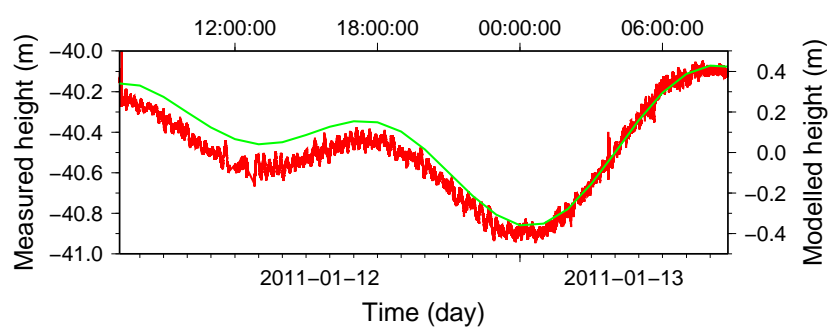

Figure 11. Modelled (green) and measured (red) tides between 12 and 13 January 2011. Surface displacements were measured on sea ice near the Astrolabe ice front by differential GPS with a baseline of less than $400 \mathrm{~m}$ allowing for very accurate measurements and a noise level of less than $5 \mathrm{~cm}$.

This model was tested through our own ocean tide measurements. Vertical displacements of the nearby sea ice were recorded for a couple of days and compared to the model results (Fig. 11). Despite a small discrepancy in the amplitudes, the phasing is perfect, which allowed us to use the model for planning our surveys and comparing our time-dependent surface height measurements to actual tidal displacements (as in Sect. 4.2.2).

\subsubsection{Scaled profiles of time-differential elevation}

Ice surface elevation along profiles $[\mathrm{AB}],[\mathrm{CD}]$ and $[\mathrm{EF}]$ (Fig. 9) was measured at both high and low tides over chosen periods during which the tidal displacement was as large as possible. Measuring an entire profile (several hundred points) could sometimes last a couple of hours; therefore, the resulting profiles were not snap shots since the tide had time to evolve during the measurement period (Vaughan, 1995). Profiles were then scaled to the tidal amplitude $e$ according to Eq. (5) of Vaughan (1995):

$d=\frac{e-e^{\prime}}{p-p^{\prime}}$,

where $e, e^{\prime}, p$ and $p^{\prime}$ are surface elevation and tidal prediction at respectively high and low tides. As computed here, $d$ actually represents the observed tidal displacement normalized to tidal predictions and will hereafter be referred to as "scaled displacement".

This scaling is an indicator of the dampening in the ice surface displacements in response to the tidal forcing. Values below the unity express deviation from a fully hydrostatic response which results from the rigid bending of the ice slab. By spreading further out the actual water loading, vertical displacements just above the ocean are necessarily reduced so as to guarantee the overall force balance. This effect is all the more pronounced as the confinement of the Astrolabe Glacier ice shelf is significant. Figure 12 shows that along the transverse profile [EF] the floatation percentage only reaches a maximum of $60 \%$. As a consequence, despite increasing along-flow displacements, floatation along 


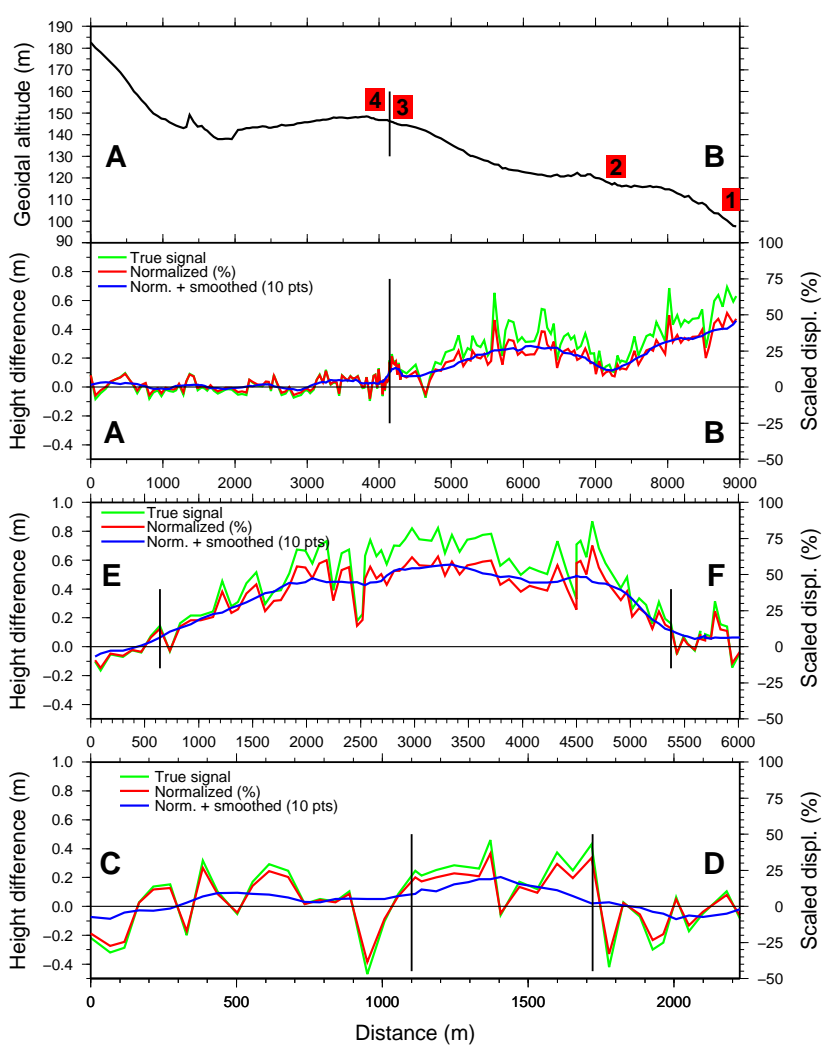

Figure 12. Difference in ice surface altitude between high and low tide for profile $[\mathrm{AB}],[\mathrm{EF}]$ and $[\mathrm{CD}]$. The green curve represent true GPS data difference, whereas the red one represents this difference scaled to the tidal amplitude (expressed as a percentage). The blue line is a smoothed version (over 10 points) of the red curve. Locations where the altitude difference becomes significant are shown by the black vertical line and define our grounding line kinematic control points. The altitude above sea level for profile $[\mathrm{AB}]$ is also displayed at the top along with the positions of the four GPS drop points along the profile (see Sect. 4.2.2).

profile $[\mathrm{AB}]$ is also limited and full recovery of tidal response would require reaching the $\mathrm{H}$ point much further seaward out of the fjord. It should be noted that these possibly large deviations from full floatation observed here only concern the response to the short-term tidal cycle and are not incompatible with an average longer-term ice slab ocean interaction much closer to hydrostatic equilibrium. Profile [AB] (Fig. 12, top) shows the ice surface altitude profile along flow and the elevation difference between low and high tides. This difference overcomes the GPS noise (here estimated to $15 \mathrm{~cm}$ ) at about $4000 \mathrm{~m}$ along the profile (Fig. 12, top; black vertical line). According to Sect. 1 and Fig. 3, this distance corresponds to point $\mathrm{X}$ somewhere between points $\mathrm{F}$ and $\mathrm{G}$. The required shifting of $X$ from $F$ towards $G$ depends on the accuracy of the kinematic method when the height difference becomes significant above the noise level (from 15 up to 20 to $30 \mathrm{~cm}$ depending on the GPS data quality).
Interestingly, an inflexion in the amplitude of the tidal movement is observable at a distance of $7000 \mathrm{~m}$ from the start of the profile and shows consistency with the hydrostatic GL getting closer (at the level of GPS drop point 2 which actually lies $7500 \mathrm{~m}$ from point A, see Fig. 9). Further downstream scaled displacements increase again and appear compatible with an hydrostatic GL that moves away. This can be seen as an illustration of surface displacements getting closer to full tidal movement as one moves away from the GL.

It will be seen in Sect. 4.2.2 that these scaled displacement are also consistent with the time-dependent GPS measurements of the ice surface at GPS drop points 1 to 4 . It is therefore possible at this stage to anticipate a more seaward GL than the spaceborne ones so far obtained (Scambos et al., 2007; Bindschadler et al., 2011) on the western margin of the glacier. Similar interpretation over profile $[\mathrm{EF}]$ allowed for determination of two extra control points from the same GPS noise level. Conversely, data for profile [CD] was more noisy due to a poor satellite GPS constellation during one of the transects. Despite an uncertainty of at least 20 to $30 \mathrm{~cm}$, a difference between high- and low-tide profiles is perceptible and has finite vertical displacements in the central part. Although the proposed positioning for the two resulting control points remains questionable over this specific profile, the presence of an uplifted central zone is confirmed by a timedependent tidal signal (see Sect. 4.2.2) already detectable at GPS drop point 3 upstream of the [CD] profile (Fig. 13). The resulting five points obtained in this way along the three GPS profiles thus represent five control points for the positioning of our kinematic GL and are displayed as red stars in Fig. 9 along with the proposed hydrostatic positioning.

\subsubsection{Time-dependent tidal measurements}

We confirm these results with continuously measured surface displacements with GPS receivers placed on the ground for several days and recording in the differential mode. Four drop points (point 1 to point 4 ) were selected along the profile $[\mathrm{AB}]$ (Figs. 4, 9; Fig. 12, top) and corresponding surface vertical displacements displayed in Figs. 13 and 14. Point 1 is situated roughly in the middle of profile $[\mathrm{EF}]$ and at the extremity of profile $[\mathrm{AB}]$ and shows a clear tidal signal whose amplitude is $55 \%$ of the predicted tidal range, consistent with the scaled altitude differences found in Fig. 12. There is a small shift in phase, with the shelf responding with a time lag of the order of one hour. A possible explanation for this phase offset is the propagation offset of the tidal signal from the open ocean to the grounding zone through the ice shelf cavity. A small anelastic component in the ice deformation is also possible as ice exhibits a viscoelastic behaviour at tidal periods (Gudmundsson, 2011).

At point 2, a phasing is still visible but the amplitude is reduced here (about $20 \%$ to $25 \%$ of the tidal amplitude as also observable on profile $[\mathrm{AB}]$ at the distance of $7500 \mathrm{~m}$ from point A) indicating the proximity of the GL less than $1 \mathrm{~km}$ 


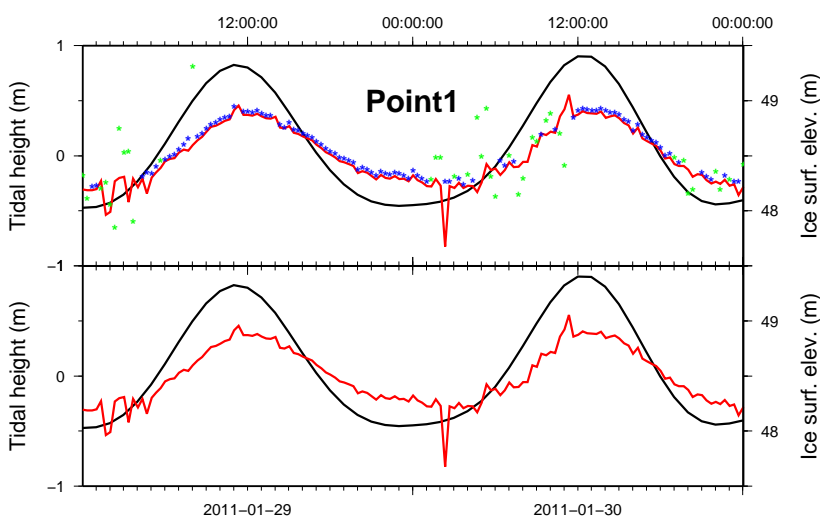

Figure 13. Time-dependent surface displacements during two days in January 2011 at point 1 . The bottom panel shows the tidal signal (black) and the vertical ice upper surface displacements obtained in Real Time Kinematic (RTK) differential mode (red). GPS data were also post-processed so as to confirm the validity of the RTK method. Corresponding results are depicted as blue stars (upper panel) when ambiguities were fixed and as green stars otherwise. The consistency between the red curve and the set of blue stars confirms the validity of the RTK approach whose results are then later systematically used in Fig. 14.

westward. Point 3 requires a vertical exaggeration to exhibit a phasing that just overcomes the GPS noise level whereas no tidal signal is detectable anymore at point 4 . Again, according to the respective positions of these last 2 points along profile $[\mathrm{AB}](4000$ and $4400 \mathrm{~m})$ such results appear fully compatible with the scaled displacements as depicted at the top of Fig. 12 and justify the positioning of the kinematic control point just in between. Moreover, point 3 exhibiting limited upper surface displacements despite being located upstream of the hydrostatic GL illustrates the specific behaviour over the $\mathrm{F}-\mathrm{G}$ distance as represented in Figs. 3 and 15. This point is either partially lifted from the ground during high tides (lying between $\mathrm{G}$ and $\mathrm{G}_{\mathrm{H}}$ ) or permanently stuck to it (between $\mathrm{F}$ and $\mathrm{G}_{\mathrm{H}}$ ), but is not considered as floating in our "hydrostatic" sense of the meaning.

\section{Elastic plate modelling}

Inspection of Fig. 9 shows kinematic control points very close to their hydrostatic counterparts. The collocation of these points is a coincidence as the measured points do not represent the same objects and/or processes (Fig. 15). Surface points from the outer fringe (between F and G; Fig. 15) can rise under the tidal forcing with their base still in contact with the bedrock (i.e. GPS point 3 for instance). By exhibiting a signal just above the GPS noise threshold, GPS point 3 probably stands around the $X$ position upstream of the hydrostatic GL. The consistency of the two methods depends on the $\mathrm{X}-\mathrm{G}$ distance as represented in the figure, which will in turn depend on both the regional rigid bending of the ice ( $\mathrm{F}-$
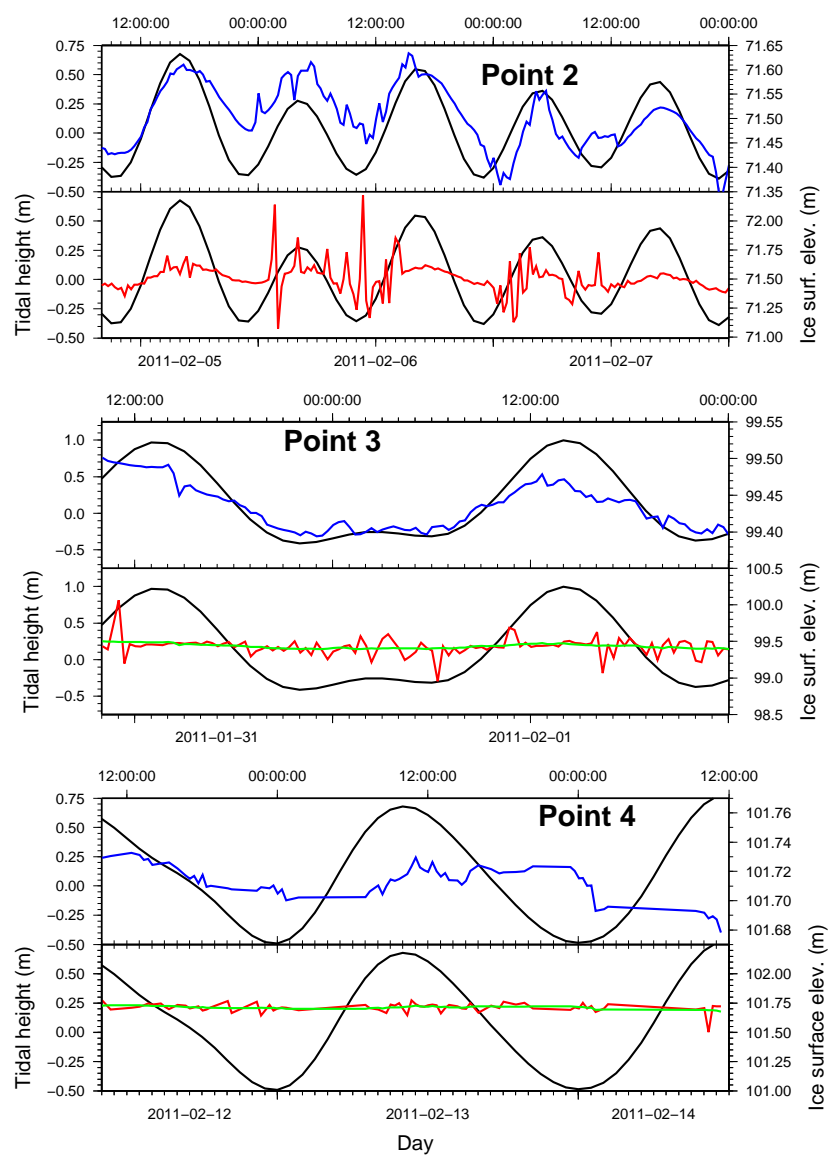

Figure 14. Comparison of the upper surface displacements and tides for point 2, 3 and 4. Black curves represent the tidal amplitude whereas the red ones stand for raw RTK GPS positions. Blue curves result from a 10-point smoothing of the raw data to which a vertical amplification has been applied (varying according to the point) in order to confirm or deny any correlation with the tides. Green curves for points 3 and 4 just represent the smoothing of raw GPS data.

G distance; see Sect. 5) and the accuracy for the kinematic method. F-G distances of the order of $0.5 \mathrm{~km}$ to $1 \mathrm{~km}$ have been reported for Petermann Glacier in Greenland (Rignot et al., 2011), but there is no indication as to why they would apply in the present case.

Modelling the tidally induced rigid behaviour of the ice slab is an independent way of assessing the $\mathrm{F}-\mathrm{G}$ distance. The elastic response of the glacier to the tidal push within the fjord is computed and corresponding results analysed in terms of (i) ice slab thickness and (ii) size of the loading pattern. The F-G distance is the result of the rigid behaviour of the plate modifying a local response where the two points would overlap. It is well known that deviation from a local hydrostatic equilibrium for a rigid slab is a function of both its flexural strength (proportional to its thickness raised to the third power) and, to a lesser degree, of the spatial extent of the load (e.g. Le Meur, 2001). In the case of Astrolabe 


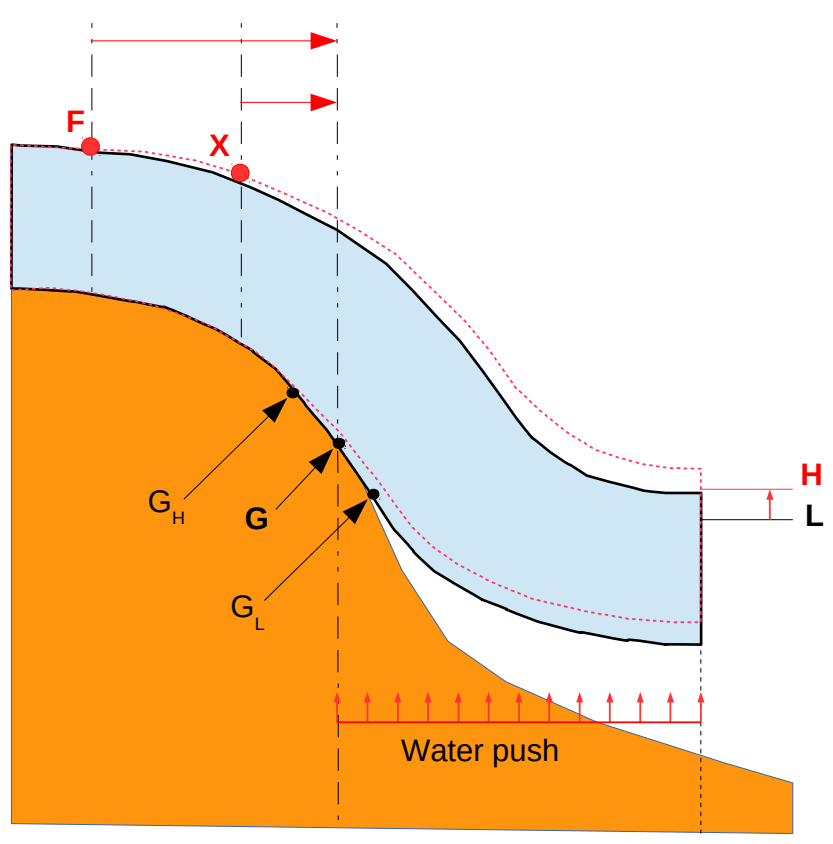

Figure 15. Hydrostatically balanced ice slab in the low-tide position onto which a water push is then applied (shown as the red arrows at the bottom), leading to the high-tide configuration (dashed lines). $\mathrm{G}_{\mathrm{L}}$ and $\mathrm{G}_{\mathrm{H}}$ respectively denote the low- and high-tide grounding lines with $\mathrm{G}$ the average position here placed in the middle and corresponding to our hydrostatic position. $\mathrm{F}$ is the landward limit of tidal upper displacements and $\mathrm{X}$ a seaward point where the uplift becomes significant enough to overcome the noise threshold of the chosen kinematic method. The red arrows at the top represent the F$\mathrm{G}$ and $\mathrm{F}-\mathrm{X}$ distances. It is important to note that the part of the slab situated between points $F$ and $G$ (theoretically $G_{H}$ ) can possibly undergo surface movements while still in contact with the bedrock as the result of the tidal bending moment of the ice slab.

Glacier, the latter effect is forced by the narrowness of the fjord, which prevents the ice from exhibiting full floatation with respect to the tidal forcing (see Sect. 4.2.1). The shape of the fjord as represented in Figs. 8 and 9 shows a varying width ranging from $5 \mathrm{~km}$ to $1 \mathrm{~km}$. Lastly, because the 2-D model used here can only deal with a uniform thickness, sensitivity tests are also performed with regard to the thickness of the plate.

\subsection{Elastic plate theory}

The 2-D elastic bending in response to a point load $q$ of a rigid elastic plate floating over an inviscid fluid of density $\rho_{\mathrm{w}}$ is given by the following constant coefficient differential equation of Brotchie and Silvester (1969) in which the momentum due to the Earth curvature can be neglected:

$D \nabla^{4} w+\rho_{\mathrm{w}} g w=q$, where $w$ is the downward deflection, $\nabla$ the 2-D gradient operator and $D$ the flexural rigidity of the plate given by

$D=\frac{E H^{3}}{12\left(1-v^{2}\right)}$,

with $E$ being the Young elastic modulus taken equal to $0.9 \mathrm{GPa}$ (Vaughan, 1995), $v$ the Poisson coefficient (0.3) and $H$ the plate thickness. The term $\rho_{\mathrm{w}} g w$ represents the buoyancy force resulting from the downward displacement $w$ within the fluid. As a consequence, the water push forcing resulting from a tidal amplitude of $\delta m$ can be expressed as $\rho_{\mathrm{w}} g \delta$ which in the absence of surface load $(q=0)$ leads to

$D \nabla^{4} w+\rho_{\mathrm{w}} g(w+\delta)=0$.

Solution to a point load $q$ is a deflection profile as a function of the scaled distance $r=x / L_{r}, x$ being the true distance and $L_{r}=\left(\frac{D}{\rho_{\mathrm{w}} g}\right)^{1 / 4}$ a flexing width. It reads

$w(r)=\frac{q}{2 \pi \sqrt{D \rho_{\mathrm{w}} g}} \operatorname{kei}(r)$,

where $q$ is a "negative" load here (corresponding to the ocean push) equal to $-\rho_{\mathrm{w}} g \delta$ and kei the Kelvin function of zeroth order. Since the elastic bending of a rigid plate is a linear process with respect to the load, the actual response to a realistic load reads as the sum of the contributions of all the points that constitute the loading pattern. The plate deformation is finally expressed in the form of the spatial convolution of that load distribution with the "unit response" as given by Eq. (6).

\subsection{Experimental set up}

In the present simulation, the domain has been digitized on a $100 \mathrm{~m} \times 100 \mathrm{~m}$ grid representing a 12 by $10 \mathrm{~km}$ rectangle over which different loading patterns are tested. The pattern of the load (water push) is here featured as a simple fjord with parallel walls and terminating in the form of a semi-circular shape whose radius is half the width of the distance between the walls (see Fig. 16). We here consider the ice resting on a low-tide ocean and then undergoing a water upward displacement of $1 \mathrm{~m}$ as corresponding to the tidal amplitudes when field measurements were carried out. The outward limit of the load (red line in the figure) is meant to match the hydrostatic grounding line as depicted in Fig. 15. Different shapes are tested with a terminal radius ranging from $500 \mathrm{~m}$ to $5 \mathrm{~km}$ as represented in green in the bottom part of Fig. 16 (implying fjord widths from 1 to $10 \mathrm{~km}$ ). The figure shows the case of the elastic rigid bulging of an $800 \mathrm{~m}$ thick ice slab in response to a $1 \mathrm{~m}$ water push over the $5 \mathrm{~km}$ wide fjord, here displayed in red.

\subsection{Results in terms of deviation from hydrostatic equilibrium}

We find that the surface response is not local, extending beyond the limits of the underlying water push. Deviation from 


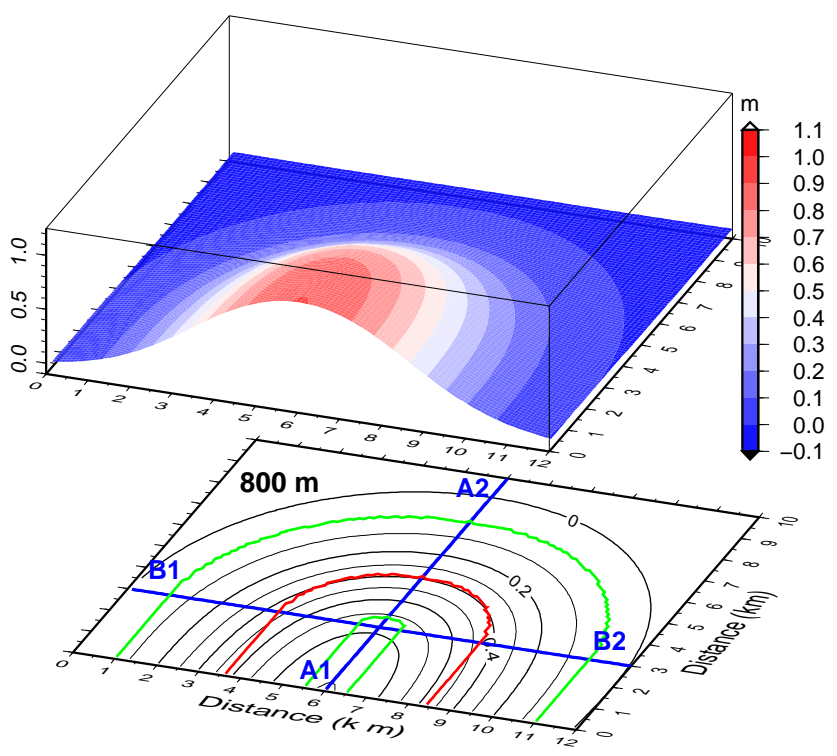

Figure 16. Elastic bulging of an $800 \mathrm{~m}$ thick ice slab (upper part) in response to a $1 \mathrm{~m}$ bottom water push exerted over the domain as outlined in red (bottom part). Green contours show the two extreme fjord geometries of the sensitivity test (see Fig. 18) whereas the black ones are the deformation contours corresponding to the 3-D upper view. Also outlined are the two cross sections represented in Fig. 17.

a local (hydrostatically equilibrated) deformation can be assessed from the spacing between the zero-deformation contour and the outline of the load. Cross sections (Fig. 17) offer a clear estimation of this rigid behaviour expressed by the shift between the termination of the load (hydrostatic point G) and the actual point of zero deformation. More specifically, the $\mathrm{G}-\mathrm{X}$ distance is here deduced from the intersection with the $0.15 \mathrm{~m}$ ice surface uplift (green line) corresponding to our estimated GPS detection threshold.

We note that the chosen example with a $5 \mathrm{~km}$ wide fjord more or less matches the configuration along profile [IJ] (Fig. 5) and agrees with partially free-floating ice on the cross profile as was actually measured. However, the model gives a central displacement of $75 \%$ of that of the tide whereas measurements are only 50 to $60 \%$. The suspected nearby ice plain close to drop point 2 where the GL comes closer to the profile (Fig. 9; not accounted for in the model) is likely responsible and would explain such a discrepancy. The main weakness of the proposed model comes from its inability to account for a varying thickness of the slab (which varies from $400 \mathrm{~m}$ to $1000 \mathrm{~m}$ along the [IJ] profile). Rather than trying to (improperly) reproduce a given configuration, it was instead decided to span a whole range of values for both the ice thickness and the loading shape that are to be expected over the glacier so as to assess the corresponding orders of magnitude for the $\mathrm{G}-\mathrm{X}$ distance.

Corresponding results are displayed in Fig. 18, where the $\mathrm{G}-\mathrm{X}$ distance is depicted as a function of both the plate thick-
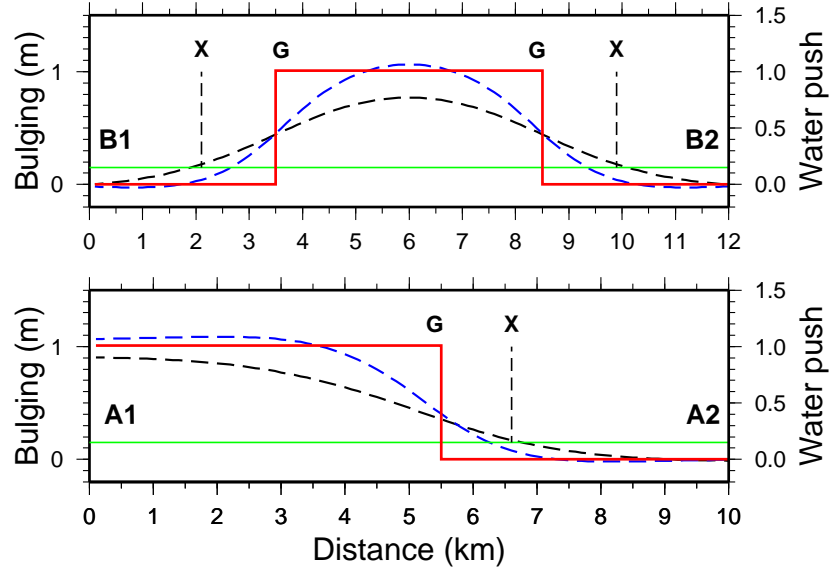

Figure 17. Longitudinal and orthogonal cross sections of both the loading pattern (red) and corresponding ice surface uplift (black) along profiles A1-A2 and B1-B2 of Fig. 16. The green horizontal line represents the smallest surface displacement of $0.15 \mathrm{~m}$ detectable by the kinematic GPS measurements. Full floatation implies a $1 \mathrm{~m}$ uplift as is almost the case on the left part of the A1-A2 profile (mouth of the fjord). The blue curve shows the same deflection profiles obtained with an elastic modulus ten times smaller than the previously adopted value of $0.9 \mathrm{GPa}$ (Vaughan, 1995). The water push is here expressed as the weight exerted over each cell of the domain $\left(100 \times 100 \times \rho_{\mathrm{w}} g \delta\right)$ in $10^{8} \mathrm{~kg}$.

ness and the semi width of the ocean forcing (curvature of the terminating fjord). The figure shows limited $\mathrm{G}-\mathrm{X}$ distances when the plate thickness is small, whatever the size of the load. It is simply the result of a shorter flexing width when the overall rigidity of the plate is reduced. Similar G-X distances are also found with a thicker slab if the load remains limited. In this latter case, the shortness is due to the smallsized load to which the rigid plate responds with small vertical displacements. Only large-scale loads associated with a thick ice slab lead to significant $\mathrm{G}-\mathrm{X}$ distances.

\section{Consistency of the hydrostatic and kinematic approaches}

The consistency between the hydrostatic and the GPS kinematic methods can now be assessed by positioning each of the five GPS control points within the parameter space (size of the load/ice thickness) and estimating the corresponding G-X distance. From the surface heights, assuming floatation, a good estimation of the ice thickness can be derived for points $\mathrm{A}^{\prime}, \mathrm{C}^{\prime}, \mathrm{D}^{\prime}, \mathrm{E}^{\prime}$, and $\mathrm{F}^{\prime}$, which gives $1050,950,950,325$ and $500 \mathrm{~m}$ respectively (the control point being here labelled according to the kinematic GPS profiles). As for the size of the tidal water forcing pattern, and given the presumed shape of the underlying fjord as shown in Figs. 8 and 9, a semi width of $1 \mathrm{~km}$ can be associated to the upstream $\mathrm{A}^{\prime}, \mathrm{C}^{\prime}$ and $\mathrm{D}^{\prime}$ control points. For downstream points, a fjord semi width of 


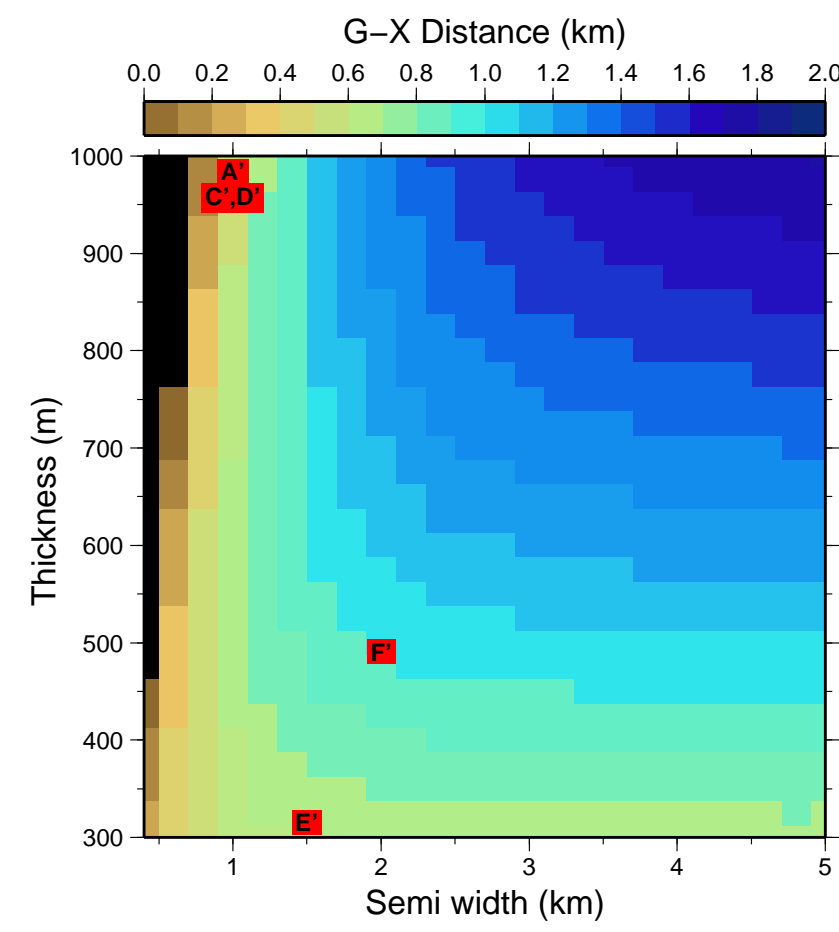

Figure 18. G-X distance $(\mathrm{km})$ as a function of the ice slab thickness and the semi width of the forcing pattern. The five kinematic GPS control points $\mathrm{A}^{\prime}, \mathrm{C}^{\prime}, \mathrm{D}^{\prime}, \mathrm{E}^{\prime}$ and $\mathrm{F}^{\prime}$ are here placed according to their specific parameter combinations. For display purposes, point $\mathrm{A}^{\prime}$ (1050 $\mathrm{m}$ ice thickness) had to be lowered to $975 \mathrm{~m}$.

approximately $2 \mathrm{~km}$ seems appropriate for control point $\mathrm{F}^{\prime}$ on the west flank of the glacier. Regarding point $\mathrm{E}^{\prime}$, the nearby inflexion of the hydrostatic GL to the southeast (Fig. 8) led us to reduce the loading curvature and adopt a lower value of $1.5 \mathrm{~km}$. The resulting parameter combinations (see their positions in Fig. 18) yield G-X distances of about $600 \mathrm{~m}$ for points $\mathrm{A}^{\prime}, \mathrm{C}^{\prime}$ and $\mathrm{D}^{\prime}$, a distance of some $900 \mathrm{~m}$ for point $\mathrm{F}^{\prime}$ and a distance of $750 \mathrm{~m}$ for point $\mathrm{E}^{\prime}$.

According to Fig. 16, the hydrostatic GL should lie seaward of the GPS control points with an offset theoretically equal to these respective distances along the GPS profiles. The computed offsets are consistent for points $\mathrm{A}^{\prime}$ and $\mathrm{C}^{\prime}$ whereas $\mathrm{D}^{\prime}$ is apparently on the wrong side. However, as said earlier, the positioning of points $\mathrm{C}^{\prime}$ and $\mathrm{D}^{\prime}$ remains questionable. Point $\mathrm{F}^{\prime}$ should be offset by $900 \mathrm{~m}$, but actually lies on the hydrostatic GL. Such a result, however, lies within the previously estimated uncertainty of $1 \mathrm{~km}$ for the hydrostatic positioning of the GL. Moreover, uncertainties in the model results are significant and the computed distances should be considered as orders of magnitude. In particular, the flexing length appears very sensitive to the elastic modulus, as can be seen in Fig. 17, where a ten times smaller modulus yields $\mathrm{X}-\mathrm{G}$ distances half as large. Adopted values for an ice shelf elastic modulus are sparse, as can be seen from the literature (spanning several orders of magnitude; see for example
Table 1 in Vaughan, 1995). Using a smaller value is a way of accounting for the anelastic part of the deformation in the form of partial viscoelastic behaviour occurring even at tidal frequencies. Finally, for point $\mathrm{E}^{\prime}$, the actual shift of $300 \mathrm{~m}$ is below the computed value, but this could reduce even further with a lower elastic modulus and in any case remains within the uncertainty estimated for the hydrostatic GL.

As a consequence, rather than indicating the absolute position of the GL, the order-of-magnitude model results show the consistency between the kinematic and the hydrostatic approaches. The hydrostatic line as outlined in Figs. 8 and 9 can therefore be considered as a good representation of the grounding line to within its associated uncertainty of a kilometre or so. The difference with the grounding lines proposed by Bindschadler et al. (2011) and Scambos et al. (2007) is in some places much larger than this uncertainty and can be as much as several kilometres, especially in the upper part and over the west flank of the glacier.

The automated procedures used for targeting specific features of surface topography (Bindschadler et al., 2011) or the large-scale filtering procedures sometimes corrupting upper surface topographic signatures (Scambos et al., 2007) can lead to additional uncertainty. Close inspection of the SPIRIT DEM reveals that these two proposed grounding lines often cross areas where the surface exhibits a convex shape rather than the concave one expected in the vicinity of the break in slope (especially on the west flank of the glacier; see Fig. 4). Last, the ASAID and Mosaic of Antarctica (MOA) grounding lines are far from the hydrostatic condition. The SPIRIT DEM gives an altitude of $130 \mathrm{ma}$ a.s.l. at the inland extremity of the $[\mathrm{QR}]$ radar profile (point $\mathrm{R}$ ), which overlaps with the two grounding lines. Assuming floatation there, a simple hydrostatic calculation (with $\rho_{\mathrm{w}}$ and $\rho_{\mathrm{i}}$ respectively equal to $1028 \mathrm{~kg} \mathrm{~m}^{-3}$ and $890 \mathrm{~kg} \mathrm{~m}^{-3}$ ) would give an ice thickness of $970 \mathrm{~m}$ which strongly conflicts with the $200 \mathrm{~m}$ inferred from the ground GPR survey (see Fig. 5).

\section{Conclusions}

The methods described here represent two independent means of mapping the grounding line of a coastal glacier such as the Astrolabe Glacier. Our study first shows that because of decoupled processes operating at different time scales, the line of uppermost surface tidal displacements does not match that of bedrock contact points resulting from the essentially hydrostatic long-term interaction of the ice with the ocean. However, it is found that under most conditions prevailing over such small glaciers like the Astrolabe (with respect to the size of the fjord and thickness of the ice), the offset between the two methods remains limited and rarely exceeds $1 \mathrm{~km}$. Moreover, the GPS kinematic method maps points which are actually closer to their hydrostatic counterparts because the uncertainty of the method requires a detection threshold to be overcome, which leads to a seaward 
shift. Both radar and GPS measurements presented here tend to confirm this consistency. Indeed, GPS measurements once corrected according to the results of a 2-D elastic plate deformation suggest a grounding line that remains within the error bars of the hydrostatic approach; these comprise uncertainties on both the ice density and the radar measurements.

Our final result is a grounding line that is significantly more seaward than those determined by Bindschadler et al. (2011) and Scambos et al. (2007). Until now, no other grounding line has been proposed over this area. In these static studies, the GL is exclusively based on surface topographic features (like the break in slope for instance). Whereas for large-scale glaciers or ice shelves the relative difference between this surface signature and the actual grounding line may be rather limited compared to the size of the ice bodies (as can be seen from the comparison with ICESat or DInSAR data in Scambos et al. (2007) for instance); however, the difference can rapidly become of the order of the glacier size for smaller bodies like the Astrolabe Glacier.

For glaciers larger than the Astrolabe, the inconsistency between the two approaches used in the present study might become more pronounced. Indeed, larger ice thicknesses associated with larger tidal loading patterns will yield enhanced rigid deviations ( $\mathrm{G}-\mathrm{F}$ distances). Mapping the grounding line assuming hydrostatic equilibrium from both lower and upper ice surface measurements (which are nowadays widely available from airborne campaigns) remains reliable as long as the associated uncertainties are minimized. If bedrock slopes are steep, as is the case with the Astrolabe, lateral shifts of the grounding line due to these errors are minimized. On the other hand, if the potentially more accurate kinematic approaches (GPS, satellite altimetric data, etc.) are used, proper correction of the "elastic plate effect" can be critical if the glacial system is large. In such cases, 3-D elastic plate modelling allowing for spatially changing ice thicknesses should ideally be considered.

\section{The Supplement related to this article is available online at doi:10.5194/tc-8-1331-2014-supplement.}

Acknowledgements. This study was funded by the Agence Nationale pour la Recherche (ANR) through the "DACOTA" project No. ANR-06-VULN-016-01 and the "ADAGE " project No. ANR09-SYSC-001. Field activities described here largely benefitted from logistical and financial support from the French polar Institute Paul Emile Victor (IPEV). E. Berthier acknowledges support from the French Space Agency (CNES) through the TOSCA and ISIS proposal \#580. ICECAP operations over Astrolabe Glacier were funded by NASA's Ice Bridge program (NNX09AR52G and NNX11AD33G to the University of Texas at Austin); WISE was funded by a grant from NASA's IPY program to the Jet Propulsion Laboratory. This work has also been supported by a grant from LabEx OSUG@2020 (Investissements d'avenir -
ANR10LABX56). Constructive comments and suggestions from two anonymous reviewers have been very helpful in improving this paper.

Edited by: J. L. Bamber

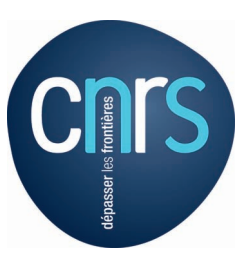

The publication of this article is financed by CNRS-INSU.

\section{References}

Bamber, J. and Bentley, C.: A comparison of satellite-altimetry and ice-thickness measurements of the Ross Ice Shelf, Antarctica, Ann. Glaciol., 20, 357-364, 1994.

Bindschadler, R., Choi, H., Wichlacz, A., Bingham, R., Bohlander, J., Brunt, K., Corr, H., Drews, R., Fricker, H., Hall, M., Hindmarsh, R., Kohler, J., Padman, L., Rack, W., Rotschky, G., Urbini, S., Vornberger, P., and Young, N.: Getting around Antarctica: new high-resolution mappings of the grounded and freely-floating boundaries of the Antarctic ice sheet created for the International Polar Year, The Cryosphere, 5, 569-588, doi:10.5194/tc-5-569-2011, 2011.

Brotchie, J. F. and Silvester, R.: On crustal flexure, J. Geophys. Res., 74, 5240-5252, 1969.

Brunt, K. M., Fricker, H. A., Padman, L., Scambos, T. A., and O'Neel, S.: Mapping the grounding zone of the Ross Ice Shelf, Antarctica, using ICESat laser altimetry, Ann. Glaciol., 51, 7179, 2010.

Corr, H. F. J., Doake, C. S. M., Jenkins, A., and Vaughan, D. G.: Investigations of an "ice-plain" in the mouth of Pine Island Glacier, Antarctica, J. Glaciol., 47, 51-57, 2001.

Craven, M., Carsey, F., Behar, A., Matthews, J., Brand, R., Elcheikh, A., Hall, S., and Treverrow, A.: Borehole imagery of meteoric and marine ice layers in the Amery Ice Shelf, East Antarctica, J. Glaciol., 51, 75-84, 2005.

Depoorter, M. A., Bamber, J. L., Griggs, J. A., Lenaerts, J. T. M., Ligtenberg, S. R. M., van den Broeke, M. R., and Moholdt, G.: Calving fluxes and basal melt rates of Antarctic ice shelves, Nature, 502, 89-92, 2013.

Durand, G., Gagliardini, O., Zwinger, T., Le Meur, E., and Hindmarsh, R.: Full Stokes modeling of marine ice sheets: influence of the grid size, Ann. Glaciol., 50, 109-114, 2009.

Fricker, H. A. and Padman, L.: Ice shelf grounding zone structure from ICESat laser altimetry, Geophys. Res. Lett., 33, L15502, doi:10.1029/2006GL026907, 2006.

Fricker, H. A., Popov, S., Allison, I., and Young, N.: Distribution of marine ice beneath the Amery Ice Shelf, Geophys. Res. Lett., 28, 2241-2244, 2001.

Gagliardini, O., Durand, G., Zwinger, T., Hindmarsh, R. C. A., and Le Meur, E.: Coupling of ice-shelf melting and buttressing is a key process in ice-sheets dynamics, Geophys. Res. Lett., 37, L14501, doi:10.1029/2010GL043334, 2010.

Goldstein, R. M., Engelhardt, H., Kamb, B., and Frolich, R. M.: Satellite Radar Interferometry for Monitoring Ice Sheet Motion: 
Application to an Antarctic Ice Stream, Science, 3, 1525-1530, 1993

Gudmundsson, G. H.: Ice-stream response to ocean tides and the form of the basal sliding law, The Cryosphere, 5, 259-270, doi:10.5194/tc-5-259-2011, 2011.

Horgan, H. J. and Anandakrishnan, S.: Static grounding lines and dynamic ice streams: Evidence from the Siple Coast, West Antarctica, Geophys. Res. Lett., 33, L18502, doi:10.1029/2006GL027091, 2006.

Joughin, I. and Padman, L.: Melting and freezing beneath FilchnerRonne Ice Shelf, Antarctica, Geophys. Res. Lett., 30, 1477, doi:10.1029/2003GL016941, 2003.

Joughin, I. R., Kwok, R., and Fahnestock, M. A.: Interferometric estimation of three-dimensional ice-flow using ascending and descending passes, IEEE Trans. Geosci. Remote Sens., 36, 25-37, 1998.

Korona, J., Berthier, E., Bernard, M., Rémy, F., and Thouvenot, E.: SPIRIT. SPOT 5 stereoscopic survey of Polar Ice: Reference Images and Topographies during the fourth International Polar Year (2007-2009), ISPRS J. Photogram. Remote Sens., 64, (2), 204212, 2009.

Legrésy, B., Wendt, A., Tabacco, I., Rémy, F., and Dietrich, R.: Influence of tides and tidal current on Mertz Glacier, Antarctica, J. Glaciol., 50, 427-435, 2004.

Le Meur, E.: Effects of a viscoelastic lithosphere on the isostatic bedrock response, Earth Planet. Sci. Lett., 188, 221-227, 2001.

Pattyn, F., Huyghe, A., De Brabander, S., and De Smedt, B.: Role of transition zones in marine ice sheet dynamics, J. Geophys. Res. Earth Surf., 111, F02004, doi:10.1029/2005JF000394, 2006.

Rignot, E.: Hinge-line migration of Petermann Gletscher, north Greenland, detected using satellite radar interferometry, J. Glaciol., 44, 469-476, 1998.

Rignot, E. and Jacobs, S. S.: Rapid bottom melting widespread near Antarctic ice sheet grounding lines, Science, 296, 2020-2023, 2002.

Rignot, E., Mouginot, J., and Scheuchl, B.: Antarctic grounding line mapping from differential satellite radar interferometry, Geophys. Res. Lett., 38, L10504, doi:10.1029/2011GL047109, 2011.
Robin, G., Doake, C. S. M., Kohnen, H., Crabtree, R. D., Jordan, S. R., and Moller, D.: Regime of the Filchner-Ronne ice shelves, Antarctica, Nature, 302, 582-586, 1983.

Scambos, T. A., Haran, T. M., Fahnestock, M. A., Painter, T. H., and Bohlander, J.: MODIS-basedh Mosaic of Antarctica (MOA) data sets: Continent-wide surface morphology and snow grain size, Remote Sens. Environ., 111, 242-257, 2007.

Schoof, C.: Ice sheet grounding line dynamics: Steady states, stability, and hysteresis, J. Geophys. Res., 112, F03S28, doi:10.1029/2006JF000664, 2007.

Shepherd, A., Ivins, E. R., Geruo, A., et al.: A Reconciled Estimate of Ice-Sheet Mass Balance, Science, 338, 1183-1189, 2012.

Van der Veen, C. J.: Fracture mechanics approach to penetration of surface crevasses on glaciers, Cold Reg. Sci. Technol., 27, 31-47, 1998.

Vaughan, D.: Tidal flexure at ice shelf margins, J. Geophys. Res., 100, 6213-6224, 1995.

Vaughan, D. G., Corr, H. F. J., Bindschadler, R. A., Dutrieux, P., Gudmundsson, G. H., Jenkins, A., Newman, T., Vornberger, P., and Wingham, D. J.: Subglacial melt channels and fracture in the floating part of Pine Island Glacier, Antarctica, J. Geophys. Res., 117, F03012, doi:10.1029/2012JF002360, 2012.

Wen, J., Jezek, K. C., Csath, B. M., Herzfeld, U. C., Farness, K. L., and Huybrechts, P.: Mass budgets of the Lambert, Mellor and Fisher Glaciers and basal fluxes beneath their flowbands on Amery Ice Shelf, Sci. China, 50, 1693-1706, 2007.

Wen, J., Wang, Y., Wang, W., Jezek, K. C., Liu, H., and Allison, I.: Basal melting and freezing under the Amery Ice Shelf, East Antarctica, J. Glaciol., 56, 81-90, 2010.

Young, D. A., Wright, A. P., Roberts, J. L., Warner, R. C., Young, N. W., Greenbaum, J. S., Schroeder, D. M., Holt, J. W., Sugden, D. E., Blankenship, D. D., van Ommen, T. D., and Siegert, M. J.: A dynamic early East Antarctic Ice Sheet suggested by ice covered fjord landscapes, Nature, 474, 72-75, 2011.

Zwally, H. J., Giovinetto, M. B., Li, J., Cornejo, H. G., Beckley, M. A., Brenner, A. C., Saba, J. L., and Yi, D.: Mass changes of the Greenland and Antarctic ice sheets and shelves and contributions to sea-level rise: 19922002, J. Glaciol., 51, 509-527, 2005. 